\title{
Detailed Micro Raman Spectroscopy Analysis of Doped Silicon Thin Film Layers and Its Feasibility for Heterojunction Silicon Wafer Solar Cells
}

\author{
Z. P. Ling ${ }^{1,2^{*}}$, J. Ge ${ }^{1,3}$, R. Stangl ${ }^{1}$, A. G. Aberle ${ }^{1,2}$, T. Mueller ${ }^{1}$ \\ ${ }^{1}$ Solar Energy Research Institute of Singapore, National University of Singapore, Singapore \\ ${ }^{2}$ Department of Electrical and Computer Engineering, National University of Singapore, Singapore \\ ${ }^{3}$ National University of Singapore Graduate School for Integrative Sciences and Engineering, Singapore \\ Email: *ling.zp@nus.edu.sg
}

Received August 14, 2013; revised September 14, 2013; accepted September 21, 2013

Copyright (C) 2013 Z. P. Ling et al. This is an open access article distributed under the Creative Commons Attribution License, which permits unrestricted use, distribution, and reproduction in any medium, provided the original work is properly cited.

\begin{abstract}
Hydrogenated doped silicon thin films deposited using RF (13.56 MHz) PECVD were studied in detail using micro Raman spectroscopy to investigate the impact of doping gas flow, film thickness, and substrate type on the film characteristics. In particular, by deconvoluting the micro Raman spectra into amorphous and crystalline components, qualitative and quantitative information such as bond angle disorder, bond length, film stress, and film crystallinity can be determined. By selecting the optimum doped silicon thin film deposition conditions, and combining our p-doped and n-doped silicon thin films in different heterojunction structures, we demonstrate both (i) an efficient field effect passivation and (ii) further improvement to c-Si/a-Si:H(i) interface defect density with observed improvement in implied open-circuit voltage $\mathrm{V}_{\mathrm{OC}}$ and minority carrier lifetimes across all injections levels of interest. In particular, the heterojunction structure $(\mathrm{a}-\mathrm{Si}: \mathrm{H}(\mathrm{p}) / \mathrm{a}-\mathrm{Si}: \mathrm{H}(\mathrm{i}) / \mathrm{c}-\mathrm{Si}(\mathrm{n}) / \mathrm{a}-\mathrm{Si}: \mathrm{H}(\mathrm{i}) / \mathrm{a}-\mathrm{Si}: \mathrm{H}(\mathrm{p}))$ demonstrates a minority carrier lifetime of $2.4 \mathrm{~ms}$ at an injection level of $10^{15} \mathrm{~cm}^{-3}$, and a high implied open-circuit voltage of $725 \mathrm{mV}$. Simulation studies reveal a strong dependence of the interface defect density $\mathrm{D}_{\mathrm{it}}$ on the heterojunction silicon wafer solar cell performance, affected by the deposition conditions of the overlying doped silicon thin film layers. Using our films, and a fitted $\mathrm{D}_{\text {it }}$ of $5 \times 10^{10}$ $\mathrm{cm}^{-2} \cdot \mathrm{eV}^{-1}$, we demonstrate that a solar cell efficiency of $\sim 22.5 \%$ can be potentially achievable.
\end{abstract}

Keywords: Raman Spectroscopy; Heterojunction Silicon Wafer Solar Cells; Doped Silicon; Simulation; Passivation

\section{Introduction}

Heterojunction with intrinsic thin layer (HIT) solar cells has proven to be a suitable candidate for cost reduction in industrial high efficiency crystalline silicon (c-Si) wafer solar cells, due to the significantly lower thermal budget requirements [1], allowing the usage of much thinner wafers $(<100 \mu \mathrm{m})$. In fact, Panasonic has recently attained record conversion efficiencies of $24.7 \%$ [2] for a wafer size of $101.8 \mathrm{~cm}^{2}$ and $98 \mu \mathrm{m}$ thick. To achieve higher conversion efficiency of heterojunction silicon wafer solar cells, the optimisation of the heavily doped thin-film emitter and back surface field (BSF) layers are important [3].

Moreover, it was found through a series of $\mathrm{H}_{2}$ effusion experiments [4], that the addition of doped silicon thin films may lower the passivation quality due to Fermi

"Corresponding author. energy dependent $\mathrm{Si}-\mathrm{H}$ bond rupture in the $a$-Si:H films, for either type of doping. This can result in silicon dangling bonds creation, counteracting intentional doping of the a-Si:H matrix and reduce the field effect passivation. Increasing doping concentration is also associated with increased defect densities, which results in Fermi level pinning, and linked to enhanced recombination at the a-Si:H/c-Si interface [5]. Hence, the optimisation of the doped silicon thin film layers is essential to its application in heterojunction silicon wafer solar cells. Despite the challenges, the successful application of doped microcrystalline silicon thin film to heterojunction silicon wafer solar cells has been demonstrated [6-11]. Various characterisation techniques are available for silicon thin film layers. In this paper, we highlight how the usage of $\mu$-Raman spectroscopy has been instrumental in our optimisation process to achieve device quality doped silicon thin films, while not degrading the underlying intrinsic 
buffer layer and its c-Si/a-Si:H(i) interface quality.

We present recent research work that complements the well-established published works on a-Si, and $\mu \mathrm{c}-\mathrm{Si}: \mathrm{H}$ related thin films [12-17]. Through the $\mu$-Raman analysis of doped silicon thin films with different microstructures, qualitative and quantitative information on the bond angle deviation, nature of film stress, correlation length and degree of short range order can be deduced. These in-house developed doped silicon thin films are further evaluated to accomplish both (i) efficient field effect passivation and (ii) interface defect density reduction evident from measured injection dependent effective lifetime curves of symmetrically passivated heterojunction lifetime samples $\left[\mathrm{p}^{+} / \mathrm{i} / \mathrm{c}-\mathrm{Si}(\mathrm{n}) / \mathrm{i} / \mathrm{p}^{+}\right]$, as well as heterojunction solar cell structure $\left[\mathrm{p}^{+} / \mathrm{i} / \mathrm{c}-\mathrm{Si}(\mathrm{n}) / \mathrm{i} / \mathrm{n}^{+}\right]$. In particular, our lifetime structure with doped layers shows improvement across all injection levels of interest. From the extracted minority carrier lifetime of $2.4 \mathrm{~ms}$ at an injection level of $10^{15} \mathrm{~cm}^{-3}$, we infer an excellent surface recombination velocity of $S_{\text {eff }} \sim 6 \mathrm{~cm} / \mathrm{s}$ if we assume a bulk lifetime of $\tau_{\text {bulk }}=\infty$ for the float zone wafer utilised in this work. This is comparable to passivation by the best $\mathrm{SiN}_{\mathrm{x}}$ or $\mathrm{AlO}_{\mathrm{x}}$ passivation schemes available elsewhere. Further simulation studies are also conducted to predict the influence of interface defect density on the effective carrier lifetime curves, and consequently on the heterojunction silicon wafer solar cell performance.

\section{Experimental Details}

Our in-house developed $\mathrm{p}$-doped emitter and n-doped back surface field layers were deposited using a conventional 13.56-MHz parallel-plate PECVD reactor (MVSystems Inc., Cluster-tool, Colorado, USA) at different $\mathrm{H}_{2} / \mathrm{SiH}_{4}$ gas flow ratios, doping gas flows, and film thickness, while maintaining the RF power density, deposition pressures, and substrate temperatures as discussed in [18].

Firstly, to investigate the impact of doping concentration on the film, the doping gas flow $\left(\mathrm{B}_{2} \mathrm{H}_{6}\right.$ and $\left.\mathrm{PH}_{3}\right)$ has been varied from $1 \mathrm{sccm}$ to $4 \mathrm{sccm}$, while maintaining the film thickness at $\sim 40 \mathrm{~nm}$ as seen in Tables 1 and 2 below. Secondly, we investigate the impact of increasing thickness for one of the chosen deposition conditions on the $\mu$-Raman results. Thirdly, given that the heterojunction silicon wafer solar cell typically consists of a symmetrical thin intrinsic a-Si:H layer for passivation [19-22] before the deposition of the thin doped layers, we also investigate the impact of substrate type on doped silicon thin film growth (i.e.: intrinsic a-Si:H and glass substrates). The doped silicon thin film on an a-Si:H substrate is prepared by depositing a thin intrinsic a-Si:H layer of $\sim 5 \mathrm{~nm}$ on a microscopic glass substrate before depositing the doped layers of $\sim 10 \mathrm{~nm}$ with different
Table 1. Overview of process parameters for p-doped silicon thin films.

\begin{tabular}{ccccc}
\hline \multirow{2}{*}{ Sample ID } & Dilution ratio & $\mathrm{H}_{2}$ flow & $\mathrm{SiH}_{4}$ flow & $\begin{array}{c}\mathrm{B}_{2} \mathrm{H}_{6}(0.5 \%) \\
\text { flow (sccm) }\end{array}$ \\
\cline { 2 - 4 } $\mathrm{R}=\mathrm{H}_{2} / \mathrm{SiH}_{4}$ & $(\mathrm{sccm})$ & $(\mathrm{sccm})$ & 1.0 \\
P1 & 32 & 194 & 6 & 1.2 \\
P2 & 32 & 194 & 6 & 1.4 \\
P3 & 32 & 194 & 6 & 1.6 \\
P4 & 32 & 194 & 6 & 1.8 \\
P5 & 32 & 194 & 6 & 2.0 \\
P6 & 32 & 194 & 6 & 2.2 \\
P7 & 32 & 194 & 6 & 2.4 \\
P8 & 32 & 194 & 6 & 2.6 \\
P9 & 32 & 194 & 6 & 2.8 \\
P10 & 32 & 194 & 6 & 3.0 \\
P11 & 32 & 194 & 6 & 3.2 \\
P12 & 32 & 194 & 6 & 4.0 \\
P13 & 32 & 194 & 6 & \\
\hline
\end{tabular}

Table 2. Overview of process parameters for $n$-doped silicon thin films.

\begin{tabular}{ccccc}
\hline \multirow{2}{*}{ Sample ID } & Dilution ratio & $\mathrm{H}_{2}$ flow & $\mathrm{SiH}_{4}$ flow & $\begin{array}{c}\mathrm{PH}_{3}(2 \%) \\
\text { flow (sccm) }\end{array}$ \\
\cline { 2 - 4 } $\mathrm{R}=\mathrm{H}_{2} / \mathrm{SiH}_{4}$ & $(\mathrm{sccm})$ & $(\mathrm{sccm})$ & 1 \\
N1 & 30 & 150 & 5 & 1.3 \\
N2 & 30 & 150 & 5 & 1.5 \\
N3 & 30 & 150 & 5 & 1.7 \\
N4 & 30 & 150 & 5 & 2 \\
N5 & 30 & 150 & 5 & 3 \\
N6 & 30 & 150 & 5 & 4 \\
N7 & 30 & 150 & 5 & \\
\hline
\end{tabular}

hydrogen dilution ratios $\mathrm{R}=\mathrm{H}_{2} / \mathrm{SiH}_{4}$. In all depositions, the RF power density, deposition pressure $p$, and substrate temperature $T$ were maintained at $0.07 \mathrm{~W} / \mathrm{cm}^{2}, 1.9$ Torr, and $180^{\circ} \mathrm{C}$ respectively.

Finally, based on the analysis, we select one of the optimum deposition condition, and investigate the quality of the doped silicon thin film layers in heterojunction carrier lifetime structures, and device structures on double-sided polished planar low-resistivity $(2.6-3.1 \Omega \mathrm{cm})$ $\mathrm{n}$-type Fz Si wafers with (100) orientation.

The $\mu$-Raman measurements were performed using the Renishaw inVia Reflex Raman microscope, and utilizes a backscattering geometry with a $514 \mathrm{~nm}$ laser line, obtained from an Argon-ion laser. The power of the incident light is $25 \mathrm{~mW}$, and a $50 \times$ objective lens giving a laser spot diameter of $5 \mu \mathrm{m}$. During each measurement, the exposure time was chosen as $10 \mathrm{~s}$, an accumulation of ten times to improve the signal to background noise ratio, and only $10 \%$ of the laser power was utilized to prevent 
crystallization of the sample. No input polarisation was utilized. All measurements were performed at room temperature. For every sample, 5 separate locations were measured to check for consistency.

In addition, the thickness and sheet resistance of the films was obtained by stylus profilometry (Dektak, Bruker Corporation) and four-point-probe setup (Cresbox, Napson Corporation) respectively. The injection dependent effective lifetime curves are measured using a contactless flash-based photoconductance decay tester (WCT-120, Sinton Consulting) operated in both transient and quasi steady state mode [23].

\section{Results and Discussion}

\subsection{Impact of Doping Gas Flow}

Firstly, the impact of the doping gas flow on the $\mu$-Raman spectra of doped silicon thin film on glass is investtigated. Figure 1 shows a decomposing of the $\mu$-Raman spectra for one of our typical microcrystalline silicon thin film into its components for amorphous Si phase, defective Si phase, and crystalline $\mathrm{Si}$ phase at 480, 510 and $520 \mathrm{~cm}^{-1}$ respectively [24] and the crystallinity of the thin film $\chi_{c}$ can be deduced based on the intensity ratio of the crystalline components to that of total integrated intensity as per Equation (1) [25].

$$
\chi_{\mathrm{c}}=\frac{\mathrm{I}_{510}+\mathrm{I}_{520}}{\mathrm{I}_{480}+\mathrm{I}_{510}+\mathrm{I}_{520}}
$$

Based on both theoretical investigations as well as experimental evidence, the relationship between root mean square (rms) bond angle dispersion $\Delta \theta$ and the full width half maximum $\Gamma$ of the amorphous silicon transverse optical (TO) Raman peak can be expressed according to

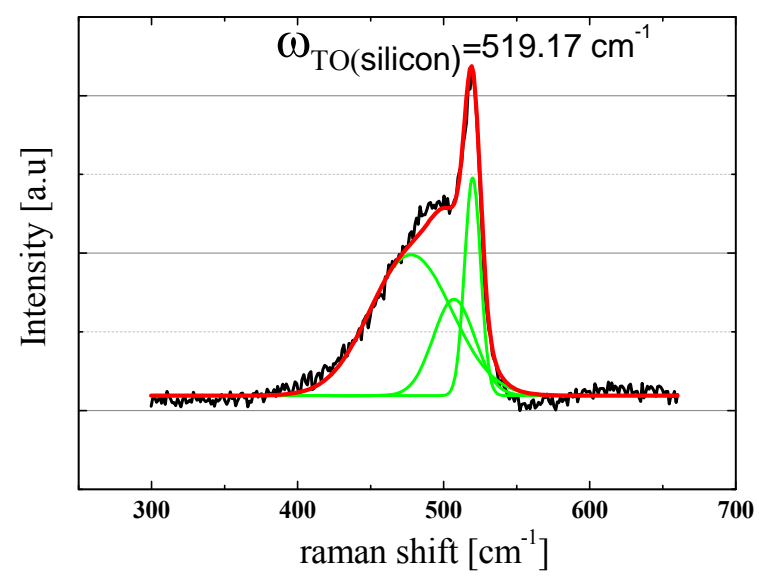

Figure 1. Raman spectra of sample P3. The black, green and red lines correspond to the measured Raman spectra, the Gaussian fits for the three silicon phases, and the resulting fit respectively. The peak position of the crystalline TO spectral band $\omega_{\text {TO(silicon) }}$ corresponds to $519.17 \mathrm{~cm}^{-1}$ for this sample.
Beeman-Tsu et al. [26] in Equation (2)

$$
\Gamma=15+6 \Delta \theta
$$

It is appropriate to highlight that the bond angle of stress-free crystalline silicon is $109.5^{\circ}$ and $\Delta \theta=0^{\circ}$.

By comparing the $\mu$-Raman spectrum in Figure 1 to a typical pure a-Si sample, the appearance of the crystalline components in the $\mu$-Raman spectrum indicates that the chosen deposition conditions facilitate the growth of silicon crystallites. By deconvolution of the $\mu$-Raman spectra for this particular doped sample, the amorphous silicon TO spectral band $\left(\omega_{\mathrm{TO}(\mathrm{a}-\mathrm{Si})}\right)$ peak position frequency, its linewidth $(\Gamma)$, and film crystallinity $\left(\chi_{\mathrm{c}}\right)$ are extracted as $477.5 \mathrm{~cm}^{-1}, 65.9 \mathrm{~cm}^{-1}$ and $39 \%$ respectively. The same information is extracted from all samples in this work.

Figures 2 and $\mathbf{3}$ show a plot of film crystallinity and conductivity as a function of the doping gas flow. As the doping gas flow is gradually increased from $1.0 \mathrm{sccm}$ to $4 \mathrm{sccm}$, the conductivity improves up to a limit before degradation occurs, while the film crystallinity reduces generally. The addition of dopants has reduced the film crystallinity, leading to an increasingly amorphous state. This implies a very narrow doping process window to get both high conductivity for the doped silicon thin film and minimum changes to the doped film microstructure, consistent with reports by Street [27] on the low doping efficiency in the range of $10^{-3}$ to $10^{-1}$. Fedders et al. [28] has attributed this low doping efficiency for the case of boron doping to the fact that most boron atoms are incorporated into threefold coordinated sites and is non-doping in this configuration, which is in line with Mott's 8-N rule of bonding [29] for amorphous semiconductors.

Our extracted film crystallinity and conductivity as a function of doping flow provides an alternative support to the above claims, and highlights the importance of doping flow optimisation amid other deposition parameters. The optimum doping gas flow for the p-doped silicon thin film and n-doped silicon thin film was found to be $\mathrm{B}_{2} \mathrm{H}_{6}=2.2 \mathrm{sccm}$ and $\mathrm{PH}_{3}=2 \mathrm{sccm}$ respectively. At such doping flow, a sufficiently high conductivity for the p-doped and n-doped thin film is achievable at $1.8 \mathrm{~S} / \mathrm{cm}$ and $16 \mathrm{~S} / \mathrm{cm}$ respectively. Increasing doping flow beyond the optimum point will only increase non-electrically active dopant atoms, which can act as recombination centers for minority carriers in a solar cell device, hence reducing the current collection efficiency.

Figures 4 and $\mathbf{5}$ show a plot of the deconvoluted amorphous silicon TO Raman peak position frequency $\left(\omega_{\mathrm{TO}(\mathrm{a}-\mathrm{Si})}\right)$ and crystalline silicon TO Raman peak position frequency $\left(\omega_{\mathrm{TO} \text { (silicon) }}\right)$ for different diborane $\left(\mathrm{B}_{2} \mathrm{H}_{6}\right)$ doping gas flow. Increasing the $\mathrm{B}_{2} \mathrm{H}_{6}$ gas flow shifts the a-Si TO peak position frequency from $476 \mathrm{~cm}^{-1}$ and approaches $480 \mathrm{~cm}^{-1}$. On the contrary, the crystalline TO 


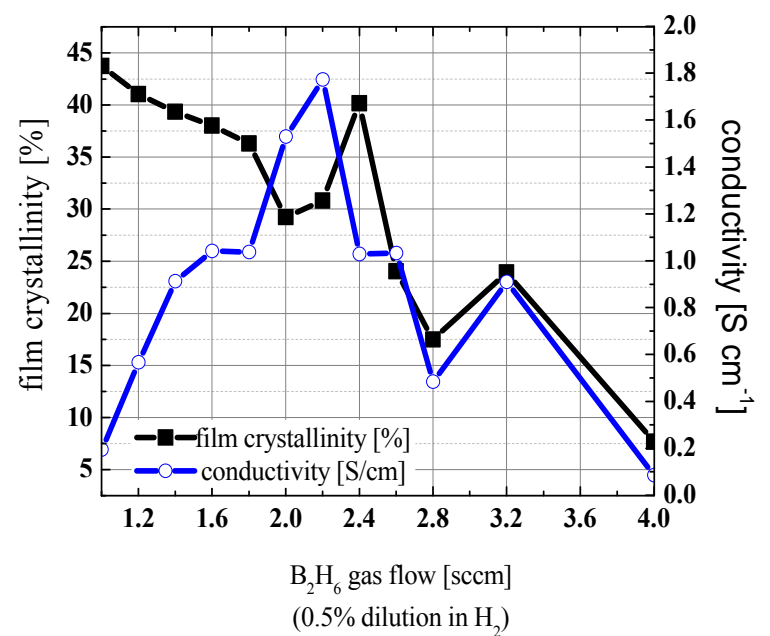

Figure 2. Comparison of film crystallinity \% and conductivity for p-doped silicon thin film with different diborane $\left(B_{2} \mathbf{H}_{6}\right)$ gas flow.

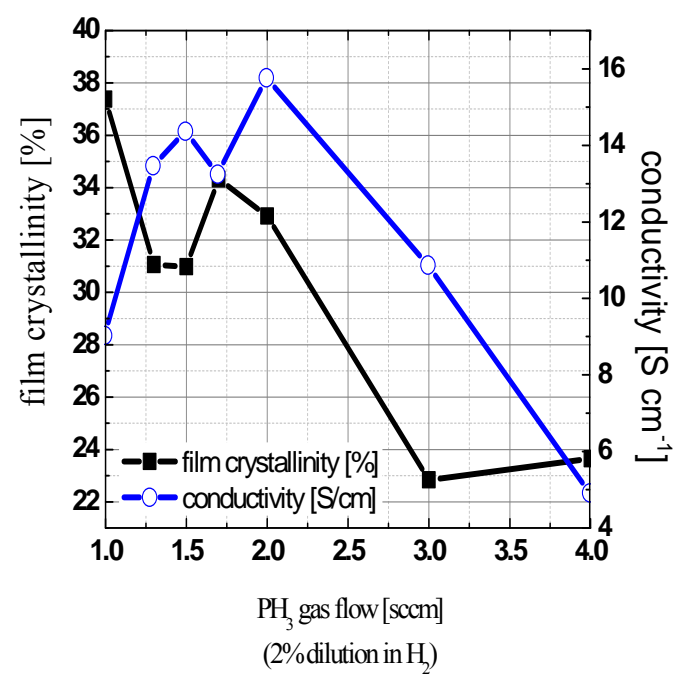

Figure 3. Comparison of film crystallinity $\%$ and conductivity for n-doped silicon thin film with different phosphine $\left(\mathrm{PH}_{3}\right)$ gas flow.

peak position frequency remained at $519.17 \mathrm{~cm}^{-1}$ for $\mathrm{B}_{2} \mathrm{H}_{6}$ doping gas flow up to $1.6 \mathrm{sccm}$, before decreasing for further increase in doping gas flow. It has been reported through 216-atom modelling of a-Si [30] that the correlation (bond) length is related to the vibrational mode localization state at different frequencies. At low frequencies below $400 \mathrm{~cm}^{-1}$, the vibrational modes are fully delocalized, localization increases above $400 \mathrm{~cm}^{-1}$ and for $\omega \geq 520 \mathrm{~cm}^{-1}$, the modes are strongly localized. In perspective, since our results shows an increasing $\omega_{\mathrm{TO}(\mathrm{a}-\mathrm{Si})}$ with doping gas flow, it suggests that the vibrational modes are increasingly being localized as well, with the reduction in the bond length, which is reasonable considering the increased quantity of incorporated dopant atoms in the same thickness and volume of the

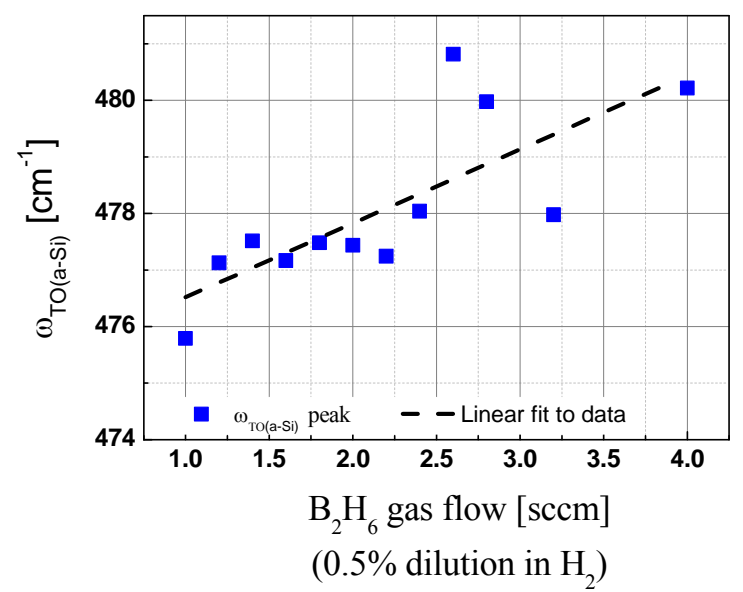

Figure 4. Impact of the diborane $\left(\mathrm{B}_{2} \mathrm{H}_{6}\right)$ gas flow on the amorphous TO Raman peak $\omega_{\mathrm{TO}(\mathrm{a}-\mathrm{Si}: \mathrm{H})}$. The line serves as a guide to the eye.

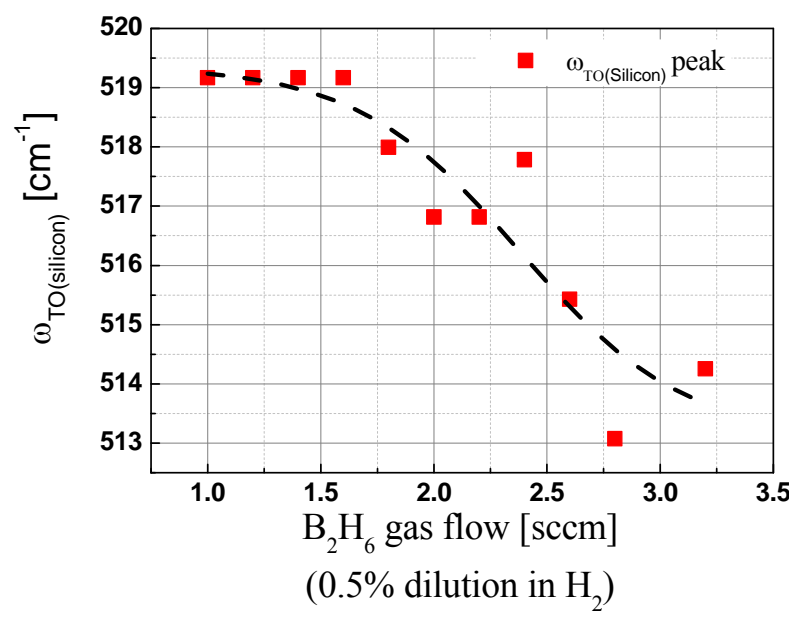

Figure 5. Impact of the diborane $\left(\mathrm{B}_{2} \mathrm{H}_{6}\right)$ gas flow on the crystalline TO Raman peak $\omega_{\text {TO(silicon) }}$ as extracted from the peak fitting of respective Raman spectra. The line serves as a guide to the eye.

deposited silicon thin film. Furthermore, as compared to a stress free frequency of $\omega_{0}=520.91 \mathrm{~cm}^{-1}$ in crystalline silicon, it is generally agreed that a Raman shift frequency larger than the stress free frequency indicates compressive stress in the sample, while a Raman shift frequency smaller than the stress-free one indicates tensile stress [31-33]. Judging from our results, it is clear that increasing the doping concentrations leads to increased tensile stress in the doped silicon thin film. Using the stress equation from Anastassakis [34] developed for a-Si:H(i) as an approximation, the stress can be deduced according to Equation (3)

$$
\sigma(\mathrm{MPa})=-250 \Delta \omega\left(\mathrm{cm}^{-1}\right)
$$

where $\sigma$ is the in-plane stress and $\Delta \omega=\omega_{\mathrm{s}}-\omega_{0}$ where $\omega_{0}$ is the optical phonon wave number of the stress free single crystal and $\omega_{\mathrm{s}}$ is the wave number of the stressed 
sample. In particular, our p-doped samples exhibit tensile stress ranging from $432 \mathrm{MPa}$ at low doping to $1.6 \mathrm{GPa}$ at high doping levels, which can be significant considering the typical thin layers to act as either the emitter or the back surface field layers. Similar discussion applies for the phosphorous-doped silicon thin film layers as observed in Figure 6. The high tensile stress can potentially degrade the underlying intrinsic buffer layer which is responsible for the surface passivation of the c-Si substrate. We highlight later in Section 3.5 the influence of the surface passivation quality on the simulated effective lifetime curves and the corresponding HIT cell efficiency.

\subsection{Film Thickness Dependency}

Secondly, with the chosen deposition conditions as per sample $\mathrm{P} 6$ with a $\mathrm{B}_{2} \mathrm{H}_{6}$ doping gas flow of $2.0 \mathrm{sccm}$, several p-doped silicon thin film samples were deposited on microscopic glass substrates with varying thickness from $20 \mathrm{~nm}$ up till $100 \mathrm{~nm}$ in $20 \mathrm{~nm}$ steps. Figure 7 shows the $\mu$-Raman spectra of these samples, while Figure 8 shows the corresponding plot of film crystallinity and conductivity. It is clear from Figures $\mathbf{7}$ and $\mathbf{8}$ that as the film thickness increase from $20 \mathrm{~nm}$ to $100 \mathrm{~nm}$, the film evolves from a purely amorphous phase into a microcrystalline phase in which film crystallinity $\chi_{\mathrm{c}}$ increases from $1 \%$ to $42 \%$. This change correlates well with an increase in conductivity from 0.06 to $4.8 \mathrm{~S} / \mathrm{cm}$.

Similarly, by deconvoluting the Raman spectra into its amorphous and crystalline silicon components, useful information can be determined to explain the observation in Figures $\mathbf{7}$ and 8. Figure 9 shows a plot of the bond angle disorder extracted from the linewidth $(\Gamma)$ of the amorphous silicon peak position frequency $\omega_{\text {TO(a-Si) }}$ using Equation (2). The bond angle disorder is observed to

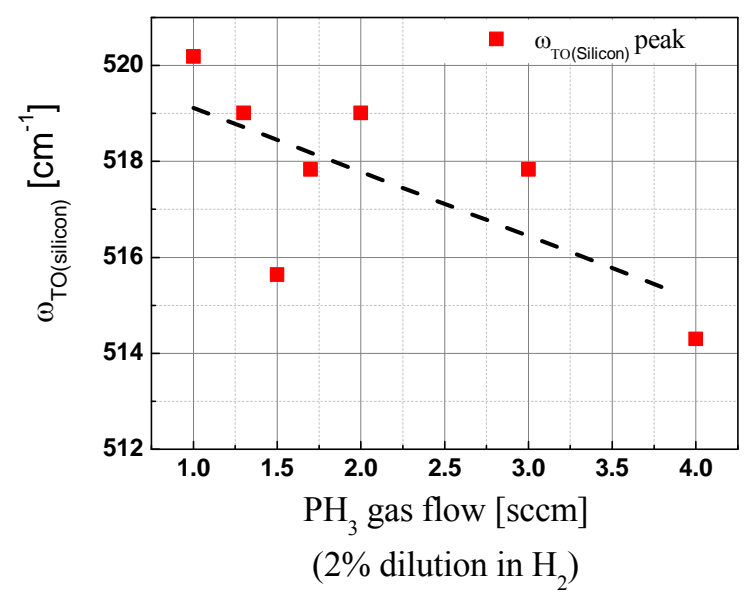

Figure 6. Impact of the phosphine $\left(\mathrm{PH}_{3}\right)$ gas flow on the crystalline TO Raman peak $\omega_{\text {TO(silicon) }}$ as extracted from the peak fitting of respective Raman spectra. The line serves as a guide to the eye.

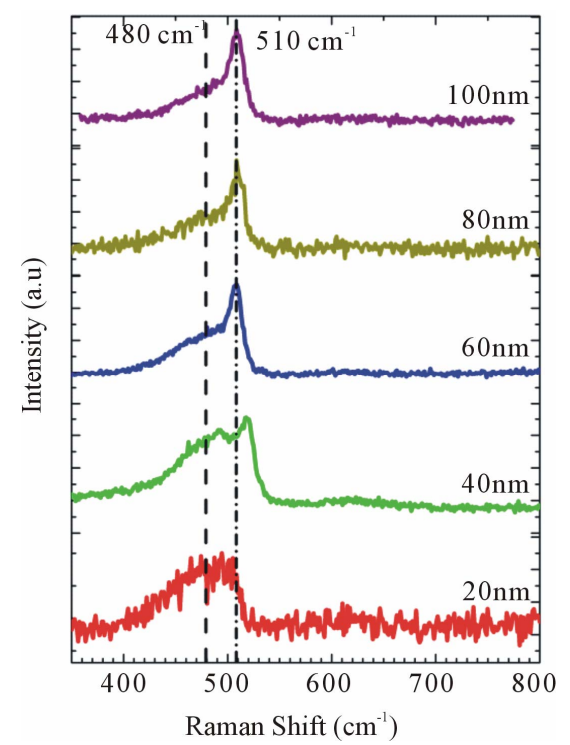

Figure 7. Raman spectra of five p-doped Si films of different thickness. Deposition conditions: pressure 1.9 Torr, substrate temp $180^{\circ} \mathrm{C}$, dilution ratio $R=32$, diborane $\left(\mathrm{B}_{2} \mathrm{H}_{6}\right)$ gas flow $2.0 \mathrm{sccm}$.

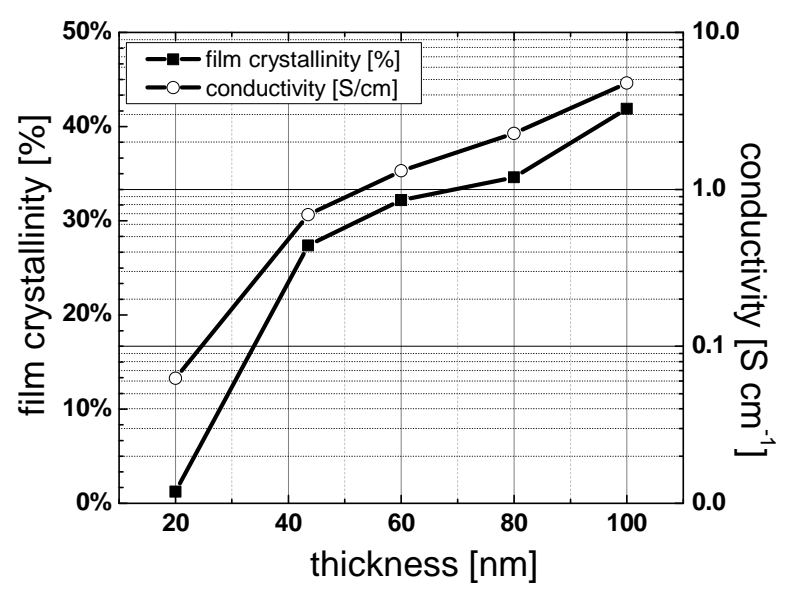

Figure 8. Impact of doped film thickness on film crystallinity and conductivity.

decrease with growing thickness, from $\Delta \theta=11^{0}$ at $20 \mathrm{~nm}$ to $\Delta \theta=8^{0}$ at $100 \mathrm{~nm}$. Furthermore, as seen in Figure 10, the amorphous silicon peak position frequency increases with increasing thickness from $474 \mathrm{~cm}^{-1}$ at $20 \mathrm{~nm}$ to 483 $\mathrm{cm}^{-1}$ at $100 \mathrm{~nm}$. Concurrently, Figure 11 shows that the crystalline silicon peak position frequency decreases with increasing thickness, from $\sim 518 \mathrm{~cm}^{-1}$ at $40 \mathrm{~nm}$ and saturates at $\sim 508 \mathrm{~cm}^{-1}$ at $60 \mathrm{~nm}, 80 \mathrm{~nm}$ and $100 \mathrm{~nm}$. From this data, it is indicative of a structural relaxation with increasing doped film thickness, as the film evolves from amorphous into microcrystalline state with increasing film crystallinity, reduced bond angle dispersion $\Delta \theta$ and reduced bond length, similar to other reports [35-40]. However, an increased tensile stress is observed with thicker doped film which is undesired. It is appropriate to 


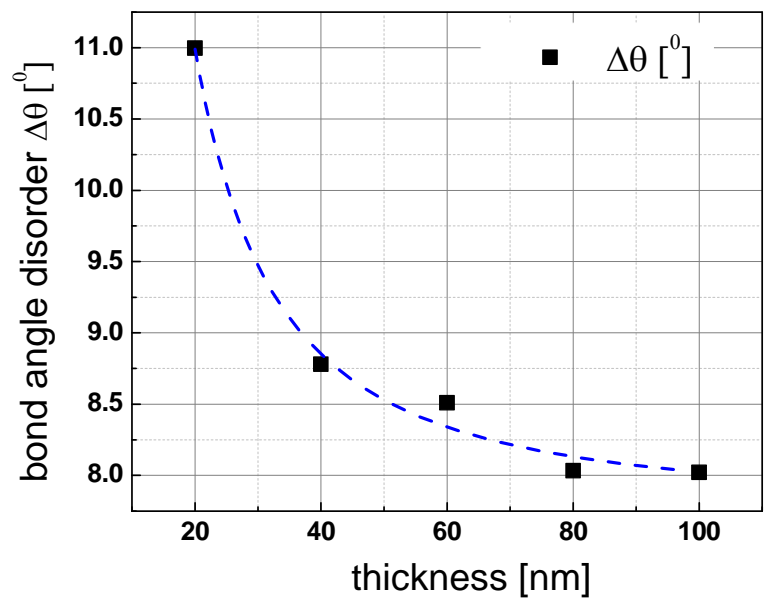

Figure 9. Variation of bond angle disorder $\Delta \theta$ on increasing p-doped silicon thin film thickness on glass substrate. The line serves as a guide to the eye.

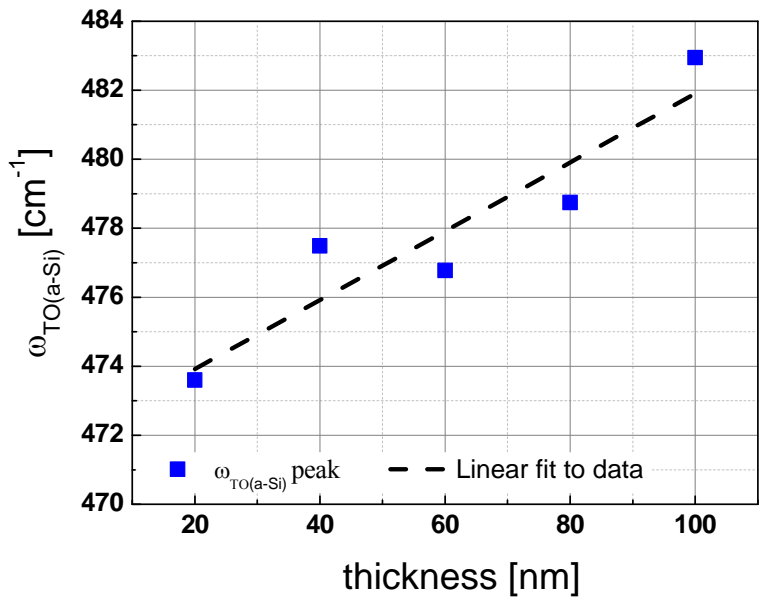

Figure 10. Variation of amorphous TO Raman peak $\omega_{\text {TO(a-Si) }}$ on increasing p-doped silicon thin film thickness on glass substrate. The line serves as a guide to the eye.

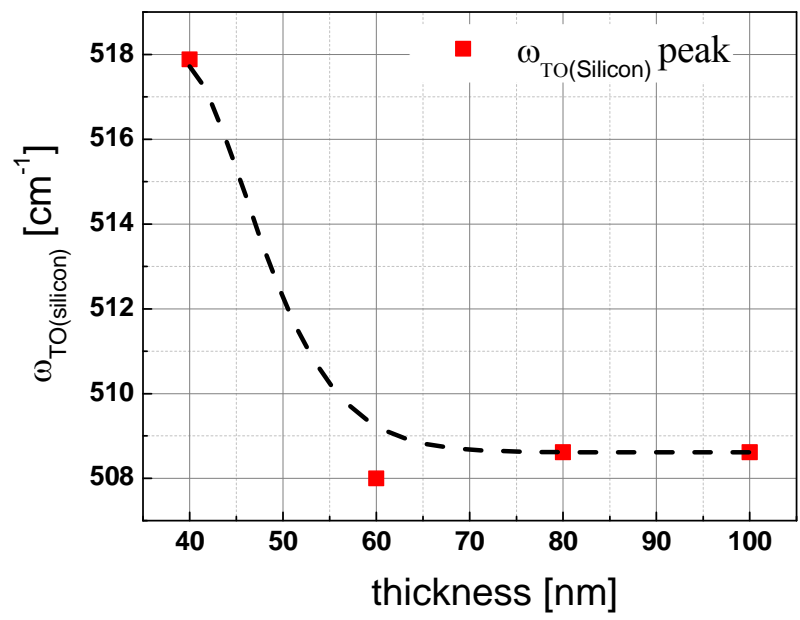

Figure 11. Variation of crystalline TO Raman peak $\omega_{\text {TO(silicon) }}$ on increasing p-doped silicon thin film thickness on glass substrate. The line serves as a guide to the eye. highlight that the deposited material is not homogenous in nature, and generally consists of a growth morphology of amorphous phase near the substrate towards an increasingly crystalline phase near the surface $[41,42]$. While our growing doped silicon thin film may experience structural relaxation, the level of structural relaxation at the amorphous phase near the substrate may not be the same as the microcrystalline phase near the surface, resulting in a higher tensile stress, as reflected from the Raman spectra. The resulting improvement in the conductivity of thicker films is not surprising due to the improved short range order as evident from the bond angle disorder reduction, improved film crystallinity, and expected improvement in doping efficiency.

Thus, in consideration of heterojunction silicon wafer solar cell device applications, the trend of thickness to crystallinity presents a trade-off between the low optical absorption of thinner doped films on one hand and better doping efficiency of thicker films on the other hand. For device application, the doped layer thickness should be around 10 to $20 \mathrm{~nm}$, implying that further conductivity optimisation of the p-doped emitter layer is required to achieve both low optical absorption and high doping efficiency.

It is also relevant to highlight reports by Cabarrocas et al. [43], Fujiwara et al. [44], and Collins et al. [41] that the nucleation properties of doped microcrystalline silicon thin film are strongly dependent on the substrate. The comparison of film growth on different substrates, such as glass, crystalline silicon, as well as hydrogenated intrinsic amorphous silicon (a-Si:H) has shown different variation of film crystallinity with increasing thickness. To enhance $\mu \mathrm{c}-\mathrm{Si}: \mathrm{H}$ growth, it is reported that a hydrogen plasma pretreatment of the a-Si:H substrate can help to generate $\mathrm{Si}$ microcrystallites at the a-Si:H surface that act as initial nuclei for enhancing doped microcrystalline silicon thin film growth. We shall investigate this in the next section.

\subsection{Influence of Substrate on Doped Silicon Thin Film Growth}

In the heterojunction silicon wafer solar cell structure, the c-Si substrate is typically symmetrically passivated by intrinsic a-Si:H thin film layers $(\sim 5 \mathrm{~nm})$ [19-22] before the deposition of the doped layers to establish the built-in potential requirements for charge separation and collection. In this section, we investigate the interaction of the deposited doped silicon thin film layers $(\sim 10 \mathrm{~nm})$ on an intrinsic a-Si:H substrate at different hydrogen dilution ratios $R=\mathrm{H}_{2} / \mathrm{SiH}_{4}$. The a-Si:H(i) substrate is prepared by depositing a $5 \mathrm{~nm}$ a-Si:H(i) layer on microscopic glass substrates $(1 \mathrm{~mm})$.

Figure 12 shows a plot of the corresponding Raman spectra for p-doped silicon thin film $(\sim 10 \mathrm{~nm})$ on an in- 


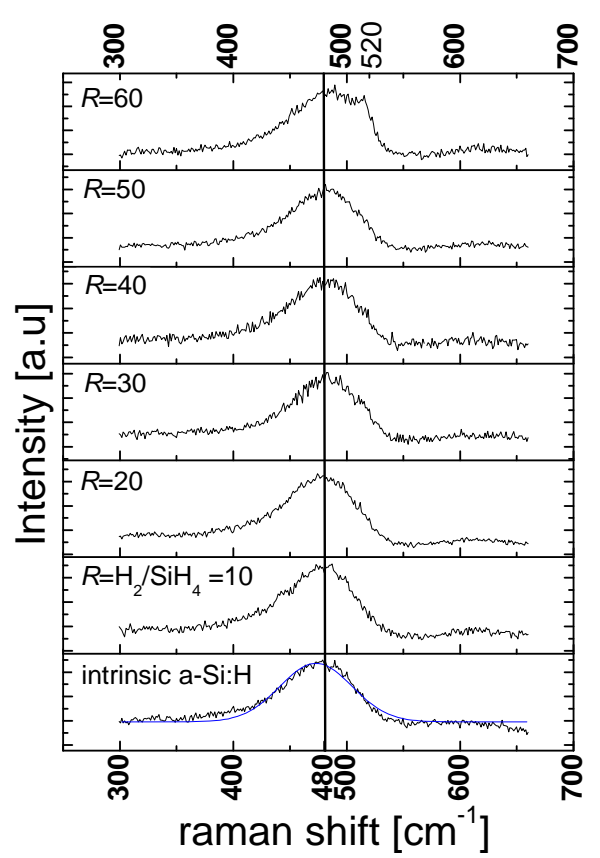

Figure 12. Comparison of the Raman spectra for borondoped silicon thin film $(\sim 10 \mathrm{~nm})$ with different hydrogen dilution ratio $R=\mathrm{H}_{2} / \mathrm{SiH}_{4}$ deposited on thin intrinsic a-Si:H $(5 \mathrm{~nm})$ layer on glass substrate.

trinsic a-Si:H substrate. For the case of the intrinsic $\mathrm{a}-\mathrm{Si} \mathrm{H}$ on glass sample, the a-Si peak position frequency is noted as $474 \mathrm{~cm}^{-1}$, a linewidth $\Gamma_{\mathrm{TO}(\mathrm{a}-\mathrm{Si})}$ of $74.5 \mathrm{~cm}^{-1}$, and a dominantly amorphous structure $\left(\chi_{\mathrm{c}}=0.16 \%\right)$. By depositing the p-doped silicon thin film $(\sim 10 \mathrm{~nm})$ with increasing hydrogen dilution ratio on the intrinsic a-Si:H substrate, a gradual shift in the Raman spectra towards higher frequency is observed. For the case of very high dilution ratio $R=60$, the crystalline TO peak position can be observed (see Figure 13) where the deconvolution of the Raman spectra shows that the amorphous silicon peak position frequency, its line-width, and crystallinity can be extracted as $475.7 \mathrm{~cm}^{-1}, 65 \mathrm{~cm}^{-1}$, and $15 \%$ respectively.

Figure 14 shows that while the intrinsic a-Si:H alone shows a rather high bond angle disorder of $9.9^{0}$, the deconvoluted Raman spectra of the combined a-Si:H(p)/ a-Si:H(i) stack shows a reduced bond angle disorder regardless of the hydrogen dilution ratio. With increasing hydrogen dilution ratios, we observe a general reduction in the bond angle disorder, coupled with increasing film crystallinity (see Figure 15). From this experiment series, the role of hydrogen during deposition of a doped layer on an a-Si:H(i) substrate is clearly evident, whereby a higher $\mathrm{H}$ flow promotes both $\mathrm{p}$-doped microcrystalline thin film growth, and reduces the combined network strain, hence lowering bond angle disorder. This finding is in line with reports by Kail et al. [45] and Chakraborty et al. [46] in which the annealing temperatures experi-

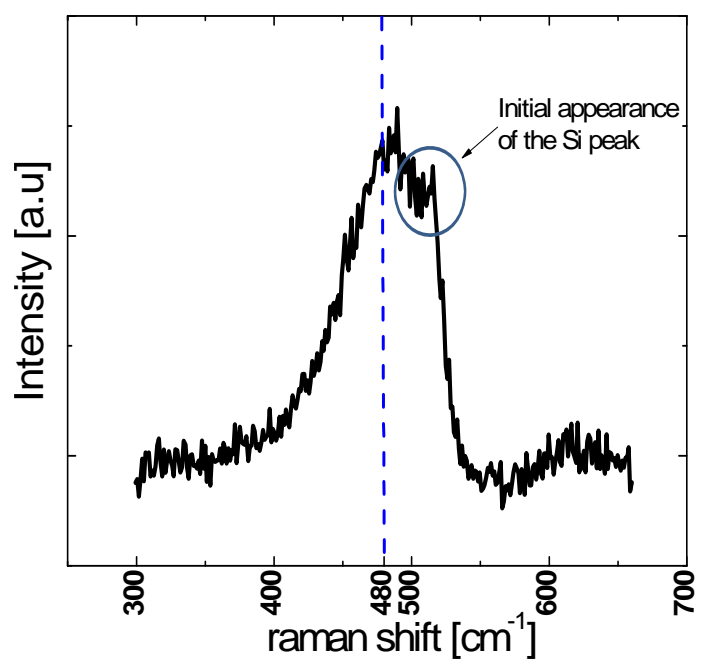

Figure 13. Raman spectra corresponding to the hydrogen dilution ratio $R=60$ of boron-doped silicon thin film $(\sim 10$ $\mathrm{nm})$ deposited on thin intrinsic a-Si:H $(5 \mathrm{~nm})$ layer on glass substrate.

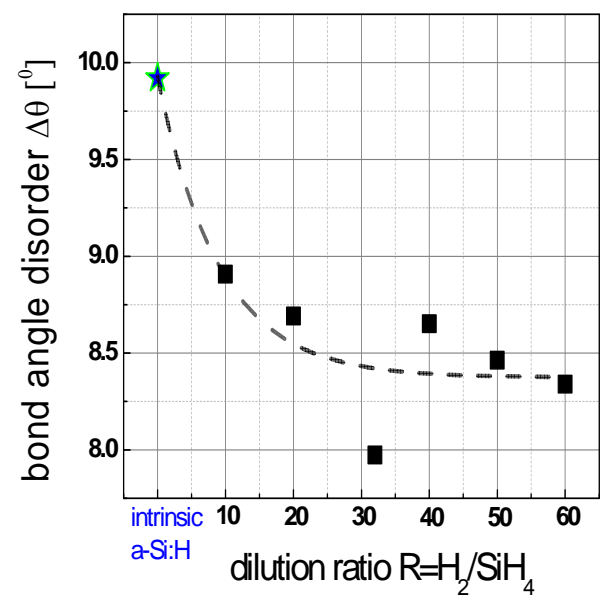

Figure 14. Impact of hydrogen dilution ratio $R$ on bond angle disorder $\Delta \theta$ for boron-doped silicon thin film $(\sim 10 \mathrm{~nm})$ deposited on thin intrinsic a-Si:H $(5 \mathrm{~nm})$ layer. The squares refer to the boron doped silicon thin film on intrinsic a-Si:H layer on glass. The star refer to that of thin intrinsic a-Si:H layer on glass substrate only.

ment on hydrogenated a-Si:H(i) samples have shown increased bond angle disorder with increased annealing temperatures due to dehydrogenation of the a-Si:H(i) samples. The hydrogen radicals can also potentially diffuse through the intrinsic buffer layer to reach the c-Si/ a-Si:H(i) interface for further passivation. Simulation studies in Section 3.5 will confirm this hypothesis using the measured effective lifetime curves of heterojunction lifetime structure $[\mathrm{p} / \mathrm{i} / \mathrm{c}-\mathrm{Si}(\mathrm{n}) / \mathrm{i} / \mathrm{p}]$ from Section 3.4.

At low $\mathrm{H}$ dilution ratio $R=10$, the combined film crystallinity indicates low impact on the underlying intrinsic a-Si:H substrate, but the deposited doped silicon thin film experiences more short range disorder as 


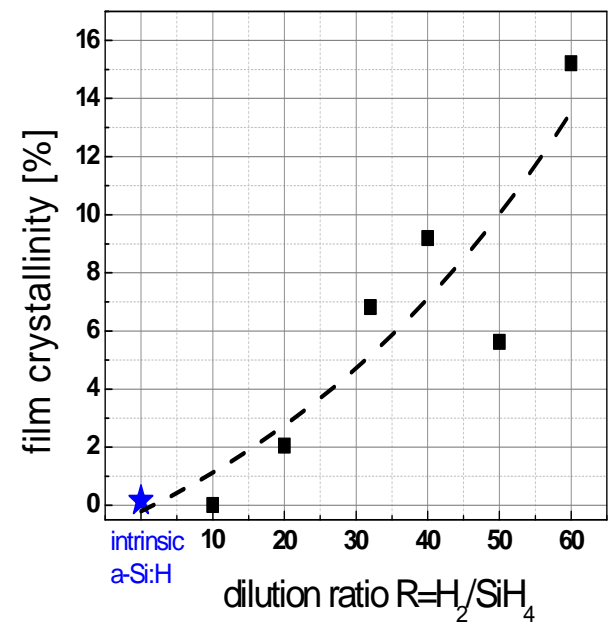

Figure 15. Impact of hydrogen dilution ratio $R$ on film crystallinity \% for boron-doped silicon thin film $(\sim 10 \mathrm{~nm})$ deposited on thin intrinsic a-Si:H (5 nm) layer. The squares refer to the boron doped silicon thin film on intrinsic a-Si:H layer on glass. The star refer to that of thin intrinsic a-Si:H layer on glass substrate only.

evident from the higher $\Delta \theta$. At very high $\mathrm{H}$ dilution ratio $R=60$, the high density of the plasma hydrogen radicals can lead to increased etching action, and degrade the underlying intrinsic buffer layer. In perspective, depositing the $\mathrm{p}$-doped silicon thin film with $\mathrm{H}$ dilution ratio $R$ in the range of $20-30$ on the intrinsic a-Si:H buffer might be a way to compromise between minimising the damage to the intrinsic buffer layer, while striving towards a microcrystalline doped silicon thin film with higher doping efficiency for solar cell application.

\subsection{Device Relevant Heterojunction Silicon Wafer Lifetime/Solar Cell Structure}

To assess the suitability of the doped silicon thin film layers for heterojunction silicon wafer solar cell application, we fabricated firstly a symmetrically passivated heterojunction carrier lifetime sample with the structure $\mathrm{p}^{+} / \mathrm{i} / \mathrm{c}-\mathrm{Si}(\mathrm{n}) / \mathrm{i} / \mathrm{p}^{+}$, as illustrated in the inset of Figure 16, and secondly a heterojunction solar cell structure $\mathrm{p}^{+} / \mathrm{i} / \mathrm{c}$ $\mathrm{Si}(\mathrm{n}) / \mathrm{i} / \mathrm{n}^{+}$, while comparing with the $\mathrm{i} / \mathrm{c}-\mathrm{Si}(\mathrm{n}) / \mathrm{i}$ structure. The chosen thickness for the intrinsic (i) layer and the p-doped layer for the carrier lifetime structure in Figure 16 are 10 and $20 \mathrm{~nm}$, respectively. The chosen thickness for the intrinsic (i) layer, p-doped and n-doped layer on the solar cell structure are 5,20 and $20 \mathrm{~nm}$ respectively. The p-doped silicon thin film is deposited with a $\mathrm{H}$ dilution ratio of 32 , and $\mathrm{B}_{2} \mathrm{H}_{6}=2.2 \mathrm{sccm}$, while the n-doped silicon thin film is deposited with a $\mathrm{H}$ dilution ratio of 30 , and $\mathrm{PH}_{3}=2 \mathrm{sccm}$ based on the analysis from earlier sections.

Over here, we demonstrate that both of our heterojunction structures showed improved minority carrier

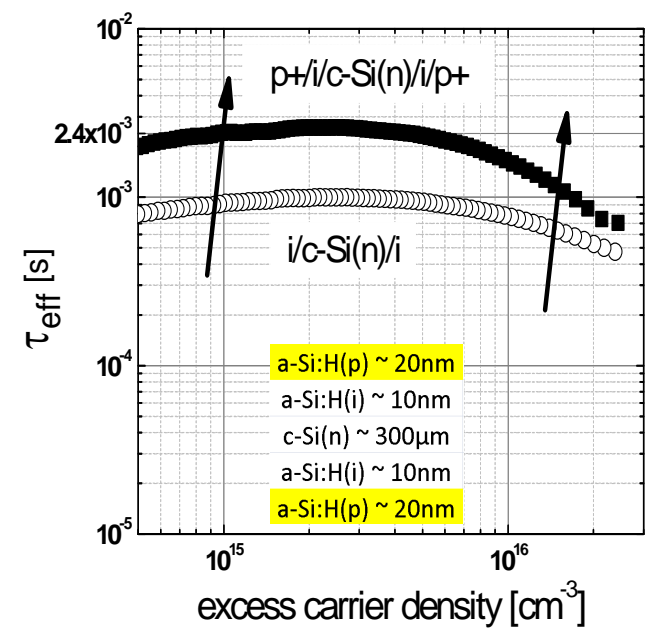

Figure 16. Effective carrier lifetime of bifacial heterojunction structure with symmetrically passivated intrinsic a$\mathrm{Si}: \mathrm{H}$ layers only (open-circles) and complete layer stack (closed-squares). Improvement in the overall lifetime with the symmetrical p-doped silicon thin film layers is observed. A high minority carrier lifetime of $2.4 \mathrm{~ms}$ is obtained at a carrier injection level of $10^{15} \mathrm{~cm}^{-3}$ for the heterojunction carrier lifetime structure $\mathbf{p}^{+} / \mathbf{i} / \mathbf{c}-\mathbf{S i}(\mathbf{n}) / \mathbf{i} / \mathbf{p}^{+}$.

lifetimes across all injection levels of interest as compared to the $\mathrm{i} / \mathrm{c}-\mathrm{Si}(\mathrm{n}) / \mathrm{i}$ structure alone. Understanding that the deposition process window for device quality doped silicon thin film is actually quite narrow, and with careful optimisation, it is possible to achieve a high degree of heterojunction interface passivation with the developed doped silicon thin films in this work. In particular, the heterojunction carrier lifetime structure $\mathrm{p}^{+} / \mathrm{i} / \mathrm{c}$ $\mathrm{Si}(\mathrm{n}) / \mathrm{i} / \mathrm{p}^{+}$in Figure 16 shows an improvement from 0.9 $\mathrm{ms}(\mathrm{i} / \mathrm{c}-\mathrm{Si}(\mathrm{n}) / \mathrm{i})$ to $2.4 \mathrm{~ms}$ at the minority carrier injection level of $10^{15} \mathrm{~cm}^{-3}$, and a corresponding implied opencircuit voltage of $725 \mathrm{mV}$ (Figure 17).

On the other hand, the heterojunction solar cell structure $\mathrm{p}^{+} / \mathrm{i} / \mathrm{c}-\mathrm{Si}(\mathrm{n}) / \mathrm{i} / \mathrm{n}^{+}$has a much thinner intrinsic a-Si:H layer $(\sim 5 \mathrm{~nm})$, and the structure of $\mathrm{i} / \mathrm{c}-\mathrm{Si}(\mathrm{n}) / \mathrm{i}$ gave a significantly lower minority carrier lifetime of $31 \mu$ s at the injection level of $10^{15} \mathrm{~cm}^{-3}$, and a lower implied open circuit voltage at $550 \mathrm{mV}$ (Figure 18). This is commonly reported to be due to reduced passivation quality by very thin intrinsic a-Si:H layers. Nonetheless, we demonstrate over here that with the application of the p-doped and n-doped layers, there is substantial improvement in the implied open circuit voltage by $\sim 100 \mathrm{mV}$ to reach 650 $\mathrm{mV}$, and minority carrier lifetime improved from $31 \mu$ s to $390 \mu$ s which is expected to arise from efficient field effect passivation complementing the chemical passivation by the intrinsic a-Si:H layers on the c-Si substrate. By the optimisation of the doping gas flow, and the hydrogen dilution ratio, it is possible to obtain doped silicon thin films with high conductivity, improved short range order, and reduced tensile stress for application in 


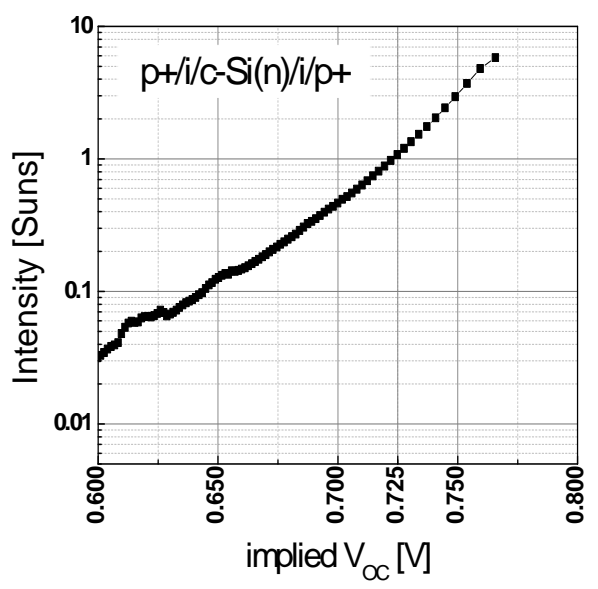

Figure 17. Implied $V_{o c}$ of the bifacial heterojunction lifetime structure as a function of intensity. The implied $V_{o c}$ at 1 sun is $725 \mathrm{mV}$.

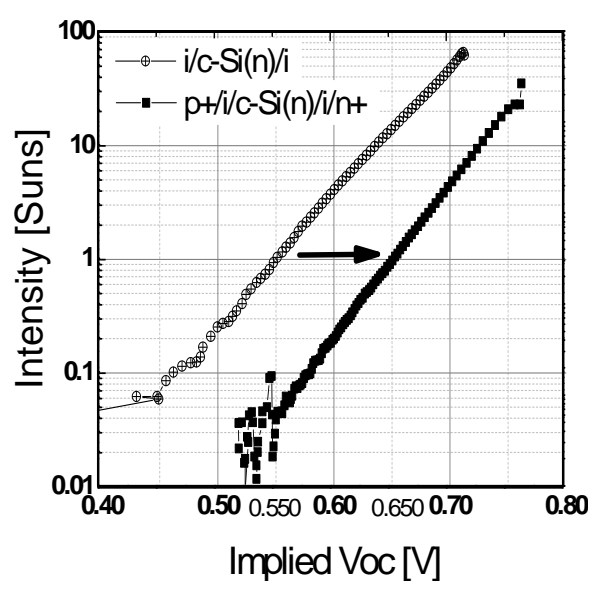

Figure 18. Implied $V_{\text {oc }}$ of the heterojunction solar cell structure. An improvement of $\sim 100 \mathrm{mV}$ in implied $V_{\text {oc }}$ is observed upon application of the p-doped and n-doped silicon thin film layers. The implied $V_{\text {oc }}$ at 1 sun for the solar cell structure $\mathrm{p}^{+} / \mathrm{i} / \mathrm{c}-\mathrm{Si}(\mathrm{n}) / \mathrm{i} / \mathrm{n}^{+}$is $650 \mathrm{mV}$. The corresponding minority carrier lifetime improves by a factor of $\sim 12$ times at the injection level of $10^{15} \mathrm{~cm}^{-3}$.

a heterojunction silicon wafer solar cell.

Although we have limited samples showing the correlation of hydrogen dilution ratio or doping flow on stacked effective lifetimes, we are still able to predict degraded effective lifetime characteristics with higher hydrogen dilution ratio or doping flow based on earlier discussions. Deviation from the optimum deposition condition can lead to degraded interface quality and lower solar cell efficiency which is part of our simulated investigations in the next section.

\subsection{Simulation Studies of Injection Dependent Effective Lifetime Curves}

There are various reports related to the calibration of amorphous silicon thin films bulk properties and c-Si/
a-Si:H(i) interface properties [47-51] for the heterojunction silicon wafer solar cell. In particular, Rahmouni et al. [50] has calibrated the simulation input parameters for a-Si:H(p), a-Si:H(n), a-Si:H(i), and interface properties with the c-Si substrate to match with measured results from Taguchi et al. [52]. Using Ref [50] as a starting point, a similar calibration has been established with Sentaurus TCAD as well (See Figure 19 for a schematic of the solar cell and Table 3 for the comparison of our simulated and experimental cell performance). A consistent set of models and parameters for the simulation of Silicon solar cells were adopted [53], including FermiDirac statistics, Klaassen's unified mobility model, radiative/Auger recombination, and its temperature dependence. Next, we perform the calibration of the bulk and interface properties of our in-house developed doped silicon thin film layers using injection dependent effective lifetime curves of symmetrically passivated n-type c-Si wafers. Figure 20 shows the resulting fit of measured data for both $[\mathrm{i} / \mathrm{c}-\mathrm{Si} / \mathrm{i}]$ and $[\mathrm{p} / \mathrm{i} / \mathrm{c}-\mathrm{Si} / \mathrm{i} / \mathrm{p}]$ lifetime structures. Table 4 shows the extracted interface properties.

For an unpassivated silicon wafer, the interface defect density $D_{i t}$ is reported to be approximately $10^{13} \mathrm{~cm}^{-2} \cdot \mathrm{eV}^{-1}$ [54]. We define the c-Si(n)/a-Si:H(i) interface defect distribution as two Gaussian distribution centered around midgap with a correlation energy of $0.2 \mathrm{eV}$. While the application of the a-Si:H(i) buffer layer with device relevant thickness $(\sim 10 \mathrm{~nm})$ has reduced $\mathrm{D}_{\text {it }}$ to $4.6 \times 10^{12}$ $\mathrm{cm}^{-2} \cdot \mathrm{eV}^{-1}$, we show in Table 4 that the further addition of the a-Si:H(p $\left.\mathrm{p}^{+}\right)$thin film layer $(\sim 20 \mathrm{~nm})$ and subsequent $\mathrm{H}$ annealing at $\sim 180^{\circ} \mathrm{C}$ is able to significantly reduce $\mathrm{D}_{\mathrm{it}}$ to $\sim 5 \times 10^{10} \mathrm{~cm}^{-2} \cdot \mathrm{eV}^{-1}$. Even without the aid of simulation, the improvement in the interface quality can be predicted from the significantly higher effective carrier lifetime of $2.4 \mathrm{~ms}$ at the injection level of $10^{15} \mathrm{~cm}^{-3}$ for the $[\mathrm{p} / \mathrm{i} / \mathrm{c}-\mathrm{Si} / \mathrm{i} / \mathrm{p}]$ lifetime structure as compared to $[\mathrm{i} / \mathrm{c}-\mathrm{Si} / \mathrm{i}]$ of $0.9 \mathrm{~ms}$. It is reasonable to assume a lower interface defect density or surface recombination velocity as a result of additional field effect passivation from the doped

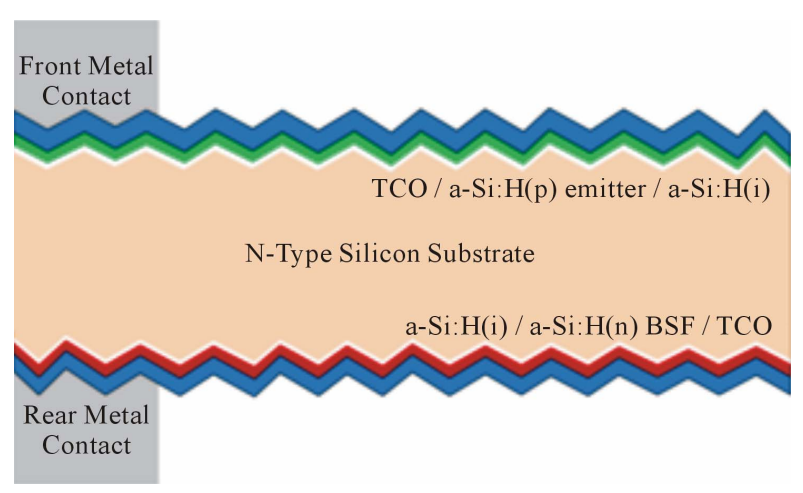

Figure 19. Schematic of a double heterojunction with intrinsic thin layer (HIT) structure. 
Table 3. Modeling of the measured cell performance parameters of double HIT structure solar cells on c-Si(n) substrate [52]. $\mathrm{N}_{\mathrm{SS}}(\mathrm{DL})$ is the interface defect density on either c-Si(n)/a-Si:H(i) interface.

\begin{tabular}{|c|c|c|c|c|c|c|c|c|}
\hline Cell Name & $\mu_{\mathrm{n}}\left(\mu_{\mathrm{p}}\right)\left(\mathrm{cm}^{2} / \mathrm{V} \mathrm{s}\right)$ & I-a-Si:H thickness (nm) & $\mathrm{N}_{\mathrm{SS}}(\mathrm{DL})\left(\mathrm{cm}^{-2}\right)$ & & $\mathrm{J}_{\mathrm{SC}}\left(\mathrm{mA} \cdot \mathrm{cm}^{-2}\right)$ & $\mathrm{V}_{\mathrm{OC}}(\mathrm{V})$ & $\mathrm{FF}(\%)$ & Efficiency (\%) \\
\hline \multirow[t]{2}{*}{ Half } & $30(6)$ & 1.5 & $2.5 \mathrm{E}+11$ & Expt & 37.4 & 0.699 & 0.776 & 20.3 \\
\hline & & & & Model & 37.22 & 0.698 & 0.778 & 20.21 \\
\hline \multirow[t]{2}{*}{ Normal } & $25(5)$ & 3.0 & $1.3 \mathrm{E}+11$ & Expt & 37.2 & 0.711 & 0.773 & 20.4 \\
\hline & & & & Model & 37.19 & 0.7113 & 0.773 & 20.45 \\
\hline \multirow[t]{2}{*}{ Double } & $15(3)$ & 6.0 & $9.0 \mathrm{E}+10$ & Expt & 36.5 & 0.718 & 0.747 & 19.6 \\
\hline & & & & Model & 36.57 & 0.718 & 0.746 & 19.58 \\
\hline \multirow[t]{2}{*}{ Triple } & $15(3)$ & 9.0 & $9.0 \mathrm{E}+10$ & Expt & 36.4 & 0.715 & 0.717 & 18.7 \\
\hline & & & & Model & 36.33 & 0.716 & 0.715 & 18.6 \\
\hline
\end{tabular}

Table 4. Extracted interface defect distribution for both $[\mathrm{i} / \mathrm{c}-\mathrm{Si}(\mathrm{n}) / \mathrm{i}]$ and $[\mathrm{p} / \mathrm{i} / \mathrm{c}-\mathrm{Si}(\mathrm{n}) / \mathrm{i} / \mathrm{p}]$ lifetime structures deposited on $\mathrm{n}$-type FZ wafers. The interface defect distribution is defined as two Gaussian distributions with correlation energy of $0.2 \mathrm{eV}$ situated around midgap. A fitting of the Gaussian interface defect density $D_{\text {it }}$ and capture cross sections $\sigma$ is performed to obtain a decent fit to measured results in Figure 20.

\begin{tabular}{|c|c|c|c|c|c|}
\hline & \multicolumn{2}{|c|}{$[\mathrm{i} / \mathrm{c}-\mathrm{Si}(\mathrm{n}) / \mathrm{i}]$} & \multicolumn{3}{|c|}{$[\mathrm{p} / \mathrm{i} / \mathrm{c}-\mathrm{Si}(\mathrm{n}) / \mathrm{i} / \mathrm{p}]$} \\
\hline & a-Si(i)/c-Si interface & a-Si(i) & $\mathrm{a}-\mathrm{Si}(\mathrm{i}) / \mathrm{c}-\mathrm{Si}$ interface & $\mathrm{a}-\mathrm{Si}(\mathrm{i})$ & $\mathrm{a}-\mathrm{Si}(\mathrm{p})$ \\
\hline $\mathrm{D}_{\mathrm{it}}\left(\mathrm{cm}^{-2} \cdot \mathrm{eV}^{-1}\right)$ & $4.6 \times 10^{12}$ & & $5 \times 10^{10}$ & & \\
\hline $\mathrm{D}_{\mathrm{it}}-$ Charged $\sigma\left(\mathrm{eV}^{-1} \cdot \mathrm{cm}^{2}\right)$ & $10^{-18}$ & & $10^{-18}$ & & \\
\hline $\mathrm{D}_{\mathrm{it}}-$ Neutral $\sigma\left(\mathrm{eV}^{-1} \cdot \mathrm{cm}^{2}\right)$ & $10^{-19}$ & & $10^{-19}$ & & \\
\hline thin film layer-Charged $\sigma\left(\mathrm{cm}^{2}\right)$ & & $10^{-14}$ & & $10^{-14}$ & $6.5 \times 10^{-15}$ \\
\hline thin film layer-Neutral $\sigma\left(\mathrm{cm}^{2}\right)$ & & $10^{-15}$ & & $10^{-15}$ & $6.5 \times 10^{-16}$ \\
\hline
\end{tabular}

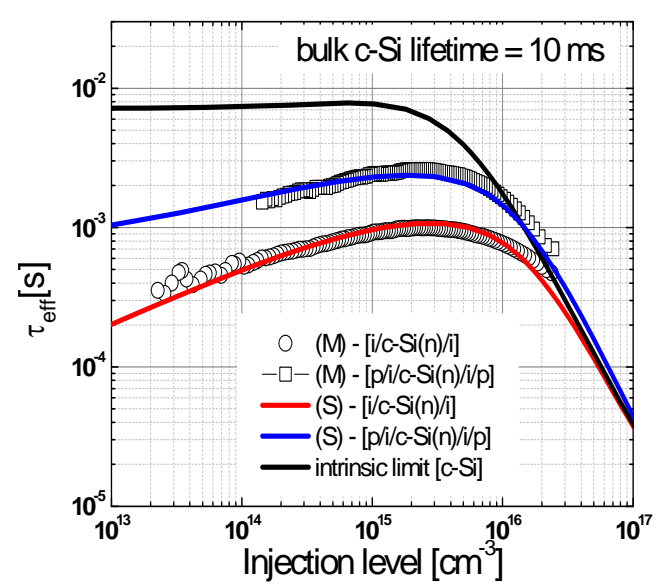

Figure 20. Fitting of the measured injection dependent minority carrier lifetime curves for $[\mathrm{i} / \mathrm{c}-\mathrm{Si} / \mathrm{i}]$ and $[\mathrm{p} / \mathrm{i} / \mathrm{c}-\mathrm{Si} / \mathbf{i} / \mathbf{p}]$ lifetime structures deposited on $\mathrm{FZ}$ wafer of resistivity $\sim 3$ ohm $\mathrm{cm}$ and $140 \mu \mathrm{m}$ thick. Also included is the intrinsic limit of c-Si(n) substrate assuming a bulk lifetime of $10 \mathrm{~ms}$ and ideal surfaces (i.e.: $S_{\mathrm{eff}}=0 \mathrm{~cm} / \mathrm{s}$ ).

layers [48] as well as benefiting from the additional $\mathrm{H}$ annealing [55] typically applied after deposition of the doped layers in our work. If the interface defect density does not reduce with the application of doped layers, we would expect to see effective lifetime curves similar to Figure 21, where the effective lifetime at the same injection level of $10^{15} \mathrm{~cm}^{-3}$ would not see major improve-

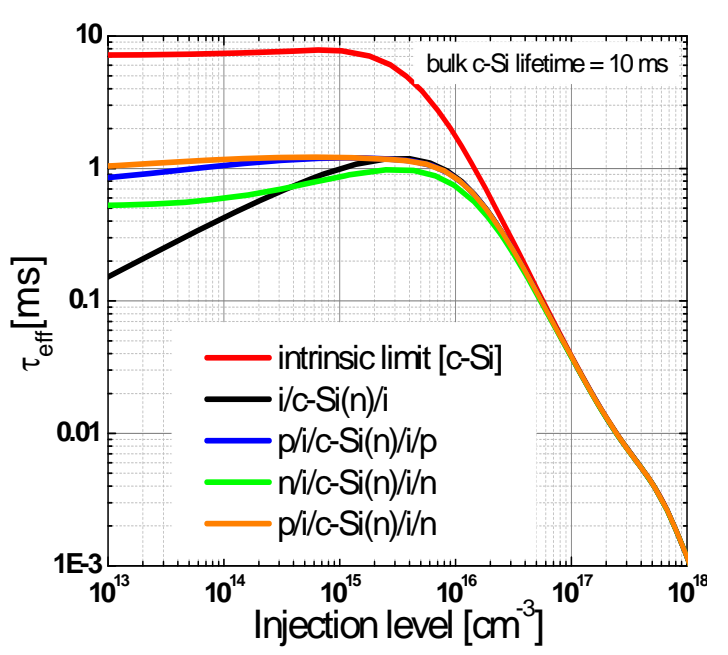

Figure 21. Simulated injection dependent effective lifetime curves of different stacked lifetime structures. Over here, the c-Si(n)/a-Si:H(i) interface defect density $D_{\text {it }}$ is assumed to be invariant at $4.6 \times 10^{12} \mathrm{~cm}^{-2} \cdot \mathrm{eV}^{-1}$ for all stacked lifetime structures. The application of doped silicon thin film layers provides field effect passivation, evident from the improved effective lifetimes at low injection levels as compared to $[i / c-S i(n) / i]$ structure alone. The c-Si(n) substrate is assumed to have a bulk lifetime of $10 \mathrm{~ms}$ and with only single midgap traps.

ments, although at low injection levels, the minority carriers lifetime are higher than $[\mathrm{i} / \mathrm{c}-\mathrm{Si}(\mathrm{n}) / \mathrm{i}]$ structures bene- 
fitting from field effect passivation.

Hence, the choice of the deposition conditions for the doped silicon thin film layers affects not only the bulk doped thin film properties, it can also have a direct impact on the interface defect density and passivation quality. Figure 22 evaluates the impact of increasing interface defect density $D_{\text {it }}$ on the injection dependent effective lifetime curves of $[\mathrm{i} / \mathrm{c}-\mathrm{Si}(\mathrm{n}) / \mathrm{i}]$ structures.

From Figure 22, the most significant impact of increasing $D_{i t}$ is the decrease of effective lifetimes at low injection levels. This has an important implication on the cell performance during low or medium incident light levels where the lower minority carrier lifetime is associated with lower diffusion length, and corresponding lower collection efficiency at the contacts. However at high injection regions, there is practically no difference in the curves as Auger recombination dominates in this region. We also observe from simulation that the bulk of the Auger recombination takes place near the front emitter and back surface field regions, since most of the photogeneration occurs near the front surface, while the back surface field regions is associated with charge collections. The lower injection levels is then associated mainly in the bulk region, where the minority carriers to be collected should have a sufficiently high diffusion lengths in order to have a higher probability of collection before recombination takes place. Table 5 shows a direct impact of varying $D_{i t}$ on the cell performance. Improving $D_{i t}$ directly improves all key cell parameters (short circuit current density $\mathrm{J}_{\mathrm{SC}}$, open-circuit voltage $\mathrm{V}_{\mathrm{OC}}$ and fill factor) bringing immediate cell efficiency gains from $20.7 \%$ at a $\mathrm{D}_{\text {it }}$ of $5.5 \times 10^{11} \mathrm{~cm}^{-2} \cdot \mathrm{eV}^{-1}$ to $22.5 \%$ for a $\mathrm{D}_{\text {it }}$ of $5 \times$ $10^{10} \mathrm{~cm}^{-2} \cdot \mathrm{eV}^{-1}$, a relative gain of $8 \%$. Having such a low $\mathrm{D}_{\mathrm{it}}$ is achievable as demonstrated in our own lifetime structures, and highlights the importance of the doped thin film optimisation process. For a less than optimum doped layer, a higher $\mathrm{D}_{\text {it }}$ is expected, and lower cell efficiencies will result.

\section{Conclusions}

In this paper, we report the application of $\mu$-Raman spectroscopy on the hydrogenated doped silicon thin film layers for application in crystalline-amorphous silicon heterojunction solar cells. Some key findings are summarised as follows:

1) With increase in doping gas flow, the film crystallinity is reduced due to low doping efficiency. Electrically inactive dopant atoms are likely to act as recombination centres and degrade solar cell performance. In addition, vibrational modes are getting more localised as observed from the shifts of the amorphous silicon TO

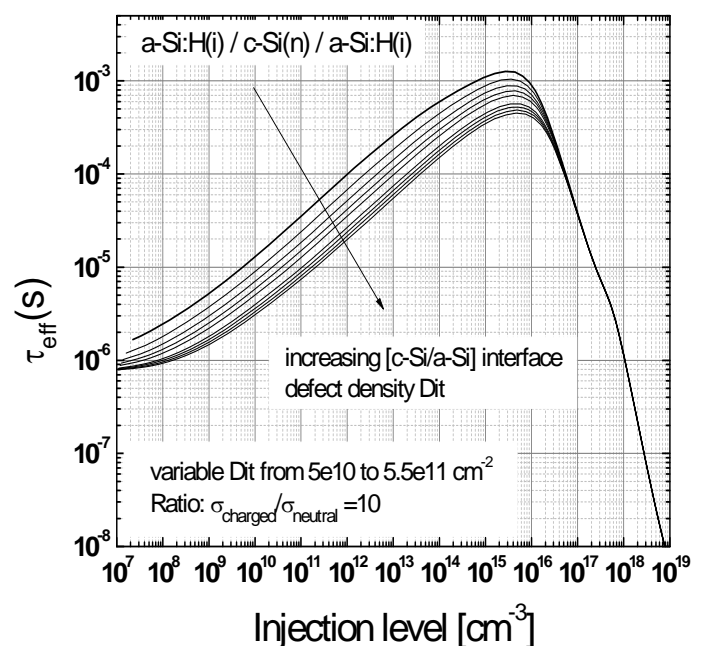

Figure 22. Impact of increasing interface defect density on effective lifetime curves for $[\mathrm{i} / \mathrm{c}-\mathrm{Si} / \mathrm{i}]$ structure.

Table 5. Influence of $\mathrm{c-Si} / \mathrm{a}-\mathrm{Si}: \mathrm{H}(\mathrm{i})$ interface defect density $\mathrm{D}_{\text {it }}$ on simulated injection dependent minority carrier lifetime curves and HIT solar cell performance. The heterojunction with thin intrinsic layer (HIT) cell consists of a [TCO/p+/i/c-Si(n)/ $\mathrm{i} / \mathbf{n}+/ \mathrm{TCO}]$ structure. Improving $\mathrm{D}_{\mathrm{it}}$ directly improves solar cell performance.

\begin{tabular}{cccccccc}
\hline Dit $\left(\mathrm{cm}^{-2}\right)$ & Charged $\sigma\left(\mathrm{cm}^{2}\right)$ & Neutral $\sigma\left(\mathrm{cm}^{2}\right)$ & Simulated $\tau_{\text {eff }}(\mathrm{s}) @ 1 \mathrm{e} 15 \mathrm{~cm}^{-3}[\mathrm{i} / \mathrm{c}-\mathrm{Si} / \mathrm{i}]$ & $\mathrm{Jsc}\left(\mathrm{mA} / \mathrm{cm}^{2}\right)$ & Voc $(\mathrm{V})$ & FillFac $(\%)$ & Eff $(\%)$ \\
\hline $5.00 \mathrm{E}+10$ & $2.00 \mathrm{E}-17$ & $2.00 \mathrm{E}-18$ & $1.45 \mathrm{E}-03$ & 37.58 & 0.743 & 80.59 & 22.506 \\
$1.00 \mathrm{E}+11$ & $2.00 \mathrm{E}-17$ & $2.00 \mathrm{E}-18$ & $1.10 \mathrm{E}-03$ & 37.54 & 0.740 & 79.99 & 22.217 \\
$1.50 \mathrm{E}+11$ & $2.00 \mathrm{E}-17$ & $2.00 \mathrm{E}-18$ & $8.78 \mathrm{E}-04$ & 37.50 & 0.737 & 79.48 & 21.966 \\
$2.00 \mathrm{E}+11$ & $2.00 \mathrm{E}-17$ & $2.00 \mathrm{E}-18$ & $7.40 \mathrm{E}-04$ & 37.46 & 0.734 & 79.07 & 21.739 \\
$2.50 \mathrm{E}+11$ & $2.00 \mathrm{E}-17$ & $2.00 \mathrm{E}-18$ & $6.33 \mathrm{E}-04$ & 37.41 & 0.731 & 78.76 & 21.545 \\
$3.00 \mathrm{E}+11$ & $2.00 \mathrm{E}-17$ & $2.00 \mathrm{E}-18$ & $5.52 \mathrm{E}-04$ & 37.37 & 0.729 & 78.48 & 21.365 \\
$3.50 \mathrm{E}+11$ & $2.00 \mathrm{E}-17$ & $2.00 \mathrm{E}-18$ & $4.94 \mathrm{E}-04$ & 37.33 & 0.726 & 78.28 & 21.202 \\
$4.00 \mathrm{E}+11$ & $2.00 \mathrm{E}-17$ & $2.00 \mathrm{E}-18$ & $4.46 \mathrm{E}-04$ & 37.29 & 0.723 & 78.10 & 21.052 \\
$4.50 \mathrm{E}+11$ & $2.00 \mathrm{E}-17$ & $2.00 \mathrm{E}-18$ & $4.09 \mathrm{E}-04$ & 37.24 & 0.721 & 77.94 & 20.916 \\
$5.00 \mathrm{E}+11$ & $2.00 \mathrm{E}-17$ & $2.00 \mathrm{E}-18$ & $3.72 \mathrm{E}-04$ & 37.20 & 0.718 & 77.81 & 20.782 \\
$5.50 \mathrm{E}+11$ & $2.00 \mathrm{E}-17$ & $2.00 \mathrm{E}-18$ & $3.43 \mathrm{E}-04$ & 37.16 & 0.716 & 77.74 & 20.668 \\
\hline
\end{tabular}


Raman peak to higher frequencies. The corresponding crystalline TO Raman peak downshifts to lower frequencies, indicating higher tensile stress in film.

2) With increasing film thickness, the film evolves from amorphous into microcrystalline phase with improved conductivity. We observed reduced bond angle disorder with thickness, believed to be due to structural relaxation. Amorphous silicon TO Raman peak also shifts to higher frequencies, indicative of reduced bond length. Increased tensile stress is also observed, subjected to the growth morphology of the silicon thin film.

3) Considering a stack of doped silicon thin film layer on intrinsic a-Si:H layer, reduced bond angle disorder is observed with increasing $\mathrm{H}$ dilution ratio, indicating improved short range order. The role of the hydrogen introduced during doped film deposition is expected to reduce strain, reduce weak $\mathrm{Si}-\mathrm{Si}$ bonds, and enhance the nucleation for doped silicon thin film in the microcrystalline phase.

4) Combining our doped silicon thin film layers into different heterojunction structures has shown efficient field effect passivation and additional reduction in interface defect density, through improvement in minority carrier lifetimes across all injection levels of interest. With a thinner intrinsic a-Si:H layer, degradation in device lifetime is expected due to reduced passivation effects, but the addition of our doped silicon thin films has reduced the detrimental effects, evidenced by improvement in implied open-circuit voltage $(\sim 100 \mathrm{mV})$. By the optimisation of the doping gas flow, and the hydrogen dilution ratio, it is possible to obtain doped microcrystalline silicon thin films with high conductivity, improved short range order, and reduced tensile stress for application in a heterojunction silicon wafer solar cell.

5) By simulating a HIT cell structure with our in-house developed silicon thin films, we demonstrate improvement in all cell performance parameters with improving interface defect density $\mathrm{D}_{\text {it }}$, achievable with careful optimisation of the doped and intrinsic thin film deposition parameters. $\mu$-Raman spectroscopy has been an essential tool in this work allowing us to obtain both quantitative and qualitative information about thin film bulk properties, as well as its interaction with underlying layers, allowing us to predict the performance of these developed thin films before integration into a solar cell structure.

\section{Acknowledgements}

SERIS is sponsored by the National University of Singapore (NUS) and Singapore's National Research Foundation (NRF) through the Singapore Economic Development Board (EDB).

\section{REFERENCES}

[1] W. V. Sark, L. Korte and F. Roca, "Introduction-Phys- ics and Technology of Amorphous-Crystalline Heterostructure Silicon Solar Cells," In: W. G. J. H. M. V. Sark, L. Korte and F. Roca, Eds., Physics and Technology of Amorphous-Crystalline Heterostructure Silicon Solar Cells, Springer, Berlin, Heidelberg, 2012, pp. 1-12. http://dx.doi.org/10.1007/978-3-642-22275-7_1

[2] A. Mette, "New Concepts for Front Side Metallization of Industrial Silicon Solar Cells," Ph.D. Thesis, Fakultät für Angewandte Wissenschaften, Universität Freiburg, Freiburg im Breisgau, 2007.

[3] J. Zhao, A. Wang and M. A. Green, "Emitter Design for High-Efficiency Silicon Solar Cells. Part I: Terrestrial Cells," Progress in Photovoltaics: Research and Applications, Vol. 1, No. 3, 1993, pp. 193-202. http://dx.doi.org/10.1002/pip.4670010303

[4] S. D. Wolf and M. Kondo, "Nature of Doped a-Si:H/c-Si Interface Recombination," Journal of Applied Physics, Vol. 105, No. 10, 2009, Article ID: 103707.

http://dx.doi.org/10.1063/1.3129578

[5] L. Korte and M. Schmidt, "Investigation of Gap States in Phosphorous-Doped Ultra-Thin a-Si:H by Near-UV Photoelectron Spectroscopy," Journal of Non-Crystalline Solids, Vol. 354, No. 19-25, 2008, pp. 2138-2143.

[6] F. Einsele, P. J. Rostan, M. B. Schubert and U. Rau, "Recombination and Resistive Losses at $\mathrm{ZnO} / \mathrm{aSi}: \mathrm{H} / \mathrm{cSi}$ Interfaces in Heterojunction Back Contacts for Si Solar Cells," Journal of Applied Physics, Vol. 102, No. 9, 2007, Article ID: 094507. http://dx.doi.org/10.1063/1.2803749

[7] P. J. Rostan, U. Rau, V. X. Nguyen, T. Kirchartz, M. B. Schubert and J. H. Werner, "Low-Temperature a-Si:H/ $\mathrm{ZnO} / \mathrm{Al}$ Back Contacts for High-Efficiency Silicon Solar Cells," Solar Energy Materials \& Solar Cells, Vol. 90, No. 9, 2006, pp. 1345-1352. http://dx.doi.org/10.1016/j.solmat.2005.11.010

[8] T. Mueller, S. Schwertheim, N. Mueller, K. Meusinger, B. Wdowiak, O. Grewe and W. Fahrner, "High Efficiency Silicon Heterojunction Solar Cell Using Novel Structure," 35th IEEE Photovoltaic Specialists Conference (PVSC'10), Honolulu, 20-25 June 2010, pp. 000683-000688.

[9] T. Mueller, "Heterojunction Solar Cells (a-Si/c-Si): Investigations on PECV Deposited Hydrogenated Silicon Alloys for Use as High-Quality Surface Passivation and Emitter/BSF," Ph.D. Thesis, University of Hagen, Hagen, 2009.

[10] M. Kaneiwa, S. Okamoto, I. Yamasaki, M. Nishida and T. Nammori, "Cell Structures with Low-High Heterojunction of c-Si and [mu]c-Si: H under Rear Contact for Improvement of Efficiencies," Solar Energy Materials and Solar Cells, Vol. 34, No. 1-4, 1994, pp. 183-191. http://dx.doi.org/10.1016/0927-0248(94)90039-6

[11] M. W. M. van Cleef, J. K. Rath, F. A. Rubinelli, C. H. M. van der Werf, R. E. I. Schropp and W. F. van der Weg, "Performance of Heterojunction Microcrystalline Silicon n Crystalline Silicon Solar Cells," Journal of Applied Physics, Vol. 82, No. 12, 1997, pp. 6089-6095. http://dx.doi.org/10.1063/1.366479

[12] Z. Iqbal and S. Veprek, "Raman Scattering from Hydrogenated Microcrystalline and Amorphous Silicon," Journal of Physics C: Solid State Physics, Vol. 15, No. 2, 
1982, p. 377.

http://dx.doi.org/10.1088/0022-3719/15/2/019

[13] M. Ledinský, A. Vetushka, J. Stuchlík, A. Fejfar and J. Kočka, "Raman Mapping of Microcrystalline Silicon Thin Films with High Spatial Resolution," Physica Status Solidi (c), Vol. 7, No. 3-4, 2010, pp. 704-707.

[14] C. Droz, E. Vallat-Sauvain, J. Bailat, L. Feitknecht, J. Meier and A. Shah, "Relationship between Raman Crystallinity and Open-Circuit Voltage in Microcrystalline Silicon Solar Cells," Solar Energy Materials and Solar Cells, Vol. 81, No. 1, 2004, pp. 61-71.

http://dx.doi.org/10.1016/j.solmat.2003.07.004

[15] H. Richter, Z. P. Wang and L. Ley, "The One Phonon Raman Spectrum in Microcrystalline Silicon," Solid State Communications, Vol. 39, No. 5, 1981, pp. 625-629. http://dx.doi.org/10.1016/0038-1098(81)90337-9

[16] P. Danesh, B. Pantchev, I. Savatinova, E. Liarokapis and Y. S. Raptis, "Short Range Order and Microstructure in Hydrogenated Amorphous Silicon," Journal of Applied Physics, Vol. 69, No. 11, 1991, pp. 7656-7659. http://dx.doi.org/10.1063/1.347537

[17] P. V. Huong, D. Mencaraglia, P. Andro and J. Baixeras, "Infrared and Resonance Raman Spectroscopic Studies of Semiconductors-Doped Amorphous Silicon," Journal of Molecular Structure, Vol. 115, 1984, pp. 473-476. http://dx.doi.org/10.1016/0022-2860(84)80115-5

[18] Z. P. Ling, J. Ge, T. Mueller, J. Wong and A. G. Aberle, "Optimisation of p-Doped $\mu \mathrm{c}-\mathrm{Si}: \mathrm{H}$ Emitter Layers in Crystalline-Amorphous Silicon Heterojunction Solar Cells," Energy Procedia, Vol. 15, 2012, pp. 118-128. http://dx.doi.org/10.1016/j.egypro.2012.02.014

[19] H. Keppner, P. Torres, R. Flückiger, J. Meier, A. Shah, C. Fortmann, P. Fath, G. Willeke, K. Happle and H. Kiess, "Passivation Properties of Amorphous and Microcrystalline Silicon Layers Deposited by VHF-GD for Crystalline Silicon Solar Cells," Solar Energy Materials and Solar Cells, Vol. 34, No. 1-4, 1994, pp. 201-209. http://dx.doi.org/10.1016/0927-0248(94)90041-8

[20] J. Mitchell, D. Macdonald, A. Cuevas and J. Cornish, "Surface Passivation of n- and p-Type Crystalline Silicon Wafers by Amorphous Silicon Films," Solar 2004: Life, the Universe and Renewables, 2004, p. 7.

[21] J.-W. A. Schüttauf, K. H. M. V. D. Werf, I. M. Kielen, W. G. J. H. M. V. Sark, J. K. Rath and R. E. I. Schropp, "Excellent Crystalline Silicon Surface Passivation by Amorphous Silicon Irrespective of the Technique Used for Chemical Vapor Deposition," Applied Physics Letters, Vol. 98, No. 15, 2011, pp. 153514-153517. http://dx.doi.org/10.1063/1.3579540

[22] B. Strahm, Y. Andrault, D. Bätzner, D. Lachenal, C. Guérin, M. Kobas, J. Mai, B. Mendes, T. Schulze, G. Wahli and A. Buechel, "Uniformity and Quality of Monocrystalline Silicon Passivation by Thin Intrinsic Amorphous Silicon in a New Generation Plasma-Enhanced Chemical Vapor Deposition Reactor," Materials Research Society Symposium Proceedings, Vol. 1245, 2010, pp. 1245-A01-1245-A04.

[23] M. R. Page, E. Iwaniczko, Y. Xu, L. Roybal, R. Bauer, H.-C. Yuan, Q. Wang and D. L. Meier, "Photoconductive
Decay Lifetime and Suns-Voc Diagnostics of Efficient Heterojunction Solar Cells," 33rd IEEE Photovoltaic Specialists Conference, San Diego, 11-16 May 2008, pp. 1-4.

[24] M. J. Pelletier, "Analytical Applications of Raman Spectroscopy,” MPG Books Ltd., Bodmin, 1999

[25] D. W. Marquardt, "An Algorithm for Least-Squares Estimation of Nonlinear Parameters," Journal of the Society for Industrial and Applied Mathematics, Vol. 11, No. 2, 1963, pp. 431-441. http://dx.doi.org/10.1137/0111030

[26] D. Beeman, R. Tsu and M. F. Thorpe, "Structural Information from the Raman Spectrum of Amorphous Silicon," Physical Review B, Vol. 32, No. 2, 1985, pp. 874878. http://dx.doi.org/10.1103/PhysRevB.32.874

[27] R. A. Street, "Sweep-Out Measurements of Band-Tail Carriers in a-Si: H," Philosophical Magazine B (UK), Vol. 60, No. 2, 1989, pp. 213-236. http://dx.doi.org/10.1080/13642818908211191

[28] P. A. Fedders and D. A. Drabold, "Theory of Boron Doping in a-Si:H," Physical Review B, Vol. 56, No. 4, 1997, pp. 1864-1867. http://dx.doi.org/10.1103/PhysRevB.56.1864

[29] N. F. Mott, "Electrons in Disordered Structures," $A d$ vances in Physics, Vol. 16, No. 61, 1967, pp. 49-144. http://dx.doi.org/10.1080/00018736700101265

[30] M. Marinov and N. Zotov, "Model Investigation of the Raman Spectra of Amorphous Silicon," Physical Review $B$, Vol. 55, No. 5, 1997, pp. 2938-2944. http://dx.doi.org/10.1103/PhysRevB.55.2938

[31] E. M. Anastassakis, "Morphic Effects in Lattice Dynamics," In: G. K. Horton and A. A. Maradudin, Eds., Dynamical Properties of Solids, North-Holland Publishing Company, Amsterdam, 1980, p. 157.

[32] T. Englert, G. Abstreiter and J. Pontcharra, "Determination of Existing Stress in Silicon Films on Sapphire Substrate Using Raman Spectroscopy," Solid-State Electronics, Vol. 23, No. 1, 1980, pp. 31-33. http://dx.doi.org/10.1016/0038-1101(80)90164-1

[33] I. D. Wolf, H. E. Maes and S. K. Jones, "Stress Measurements IN Silicon Devices through Raman Spectroscopy: Bridging the Gap between Theory and Experiment," Journal of Applied Physics, Vol. 79, No. 9, 1996, pp. 7148-7156. http://dx.doi.org/10.1063/1.361485

[34] E. Anastassakis, "Physical Problems in Microelectronics," Proceedings of the 4th International School ISPPM, Varna, 12-18 May 1985, p. 128.

[35] K. Laaziri, S. Kycia, S. Roorda, M. Chicoine, J. L. Robertson, J. Wang and S. C. Moss, "High Resolution Radial Distribution Function of Pure Amorphous Silicon," Physical Review Letters, Vol. 82, No. 17, 1999, pp. 34603463. http://dx.doi.org/10.1103/PhysRevLett.82.3460

[36] R. Tsu and J. G. Hernandez, "Determination of Energy Barrier for Structural Relaxation in A-Si and A-Ge by Raman Scattering," Journal of Non-Crystalline Solids, Vol. 66, No. 1-2, 1984, pp. 109-114. http://dx.doi.org/10.1016/0022-3093(84)90307-7

[37] A. Battaglia, S. Coffa, F. Priolo, G. Compagnini and G.A. Baratta, "Low-Temperature Modifications in the Defect 
Structure of Amorphous Silicon Probed by in Situ Raman Spectroscopy," Applied Physics Letters, Vol. 63, No. 16, 1993, pp. 2204-2206. http://dx.doi.org/10.1063/1.110553

[38] P. A. Stolk, F. W. Saris, A. J. M. Berntsen, W. F. van der Weg, L. T. Sealy, R. C. Barklie, G. Krotz and G. Muller, "Contribution of Defects to Electronic, Structural, and Thermodynamic Properties of Amorphous Silicon," Journal of Applied Physics, Vol. 75, No. 11, 1994, pp. 72667286. http://dx.doi.org/10.1063/1.356662

[39] S. Roorda, W. C. Sinke, J. M. Poate, D. C. Jacobson, S. Dierker, B. S. Dennis, D. J. Eaglesham, F. Spaepen and P. Fuoss, "Structural Relaxation and Defect Annihilation in Pure Amorphous Silicon," Physical Review B, Vol. 44, No. 8, 1991, pp. 3702-3725. http://dx.doi.org/10.1103/PhysRevB.44.3702

[40] M. Ishimaru, "Atomistic Simulations of Structural Relaxation Processes in Amorphous Silicon," Journal of Applied Physics, Vol. 91, No. 2, 2002, pp. 686-689. http://dx.doi.org/10.1063/1.1425437

[41] R. W. Collins, A. S. Ferlauto, G. M. Ferreira, C. Chen, J. Koh, R. J. Koval, Y. Lee, J. M. Pearce and C. R. Wronski, "Evolution of Microstructure and Phase in Amorphous, Protocrystalline, and Microcrystalline Silicon Studied by Real Time Spectroscopic Ellipsometry," Solar Energy Materials and Solar Cells, Vol. 78, No. 1-4, 2003, pp. 143-180. http://dx.doi.org/10.1016/S0927-0248(02)00436-1

[42] G. M. Ferreira, C. Chen, R. J. Koval, J. M. Pearce, C. R. Wronski and R. W. Collins, "Optimization of Protocrystalline Silicon P-Type Layers for Amorphous Silicon N-I-P Solar Cells," Journal of Non-Crystalline Solids, Vol. 338-340, 2004, pp. 694-697. http://dx.doi.org/10.1016/j.jnoncrysol.2004.03.062

[43] P. R. i. Cabarrocas, N. Layadi, T. Heitz, B. Drévillon and I. Solomon, "Substrate Selectivity in the Formation of Microcrystalline Silicon: Mechanisms and Technological Consequences," Applied Physics Letters, Vol. 66, No. 26, 1995, pp. 3609-3611. http://dx.doi.org/10.1063/1.113803

[44] H. Fujiwara, M. Kondo and A. Matsuda, "Nucleation Mechanism of Microcrystalline Silicon from the Amorphous Phase," Journal of Non-Crystalline Solids, Vol. 338-340, 2004, pp. 97-101. http://dx.doi.org/10.1016/i.jnoncrysol.2004.02.029

[45] F. Kail, J. Farjas, P. Roura, C. Secouard, O. Nos, J. Bertomeu, F. Alzina and P. Roca i Cabarrocas, "Relaxation and Derelaxation of Pure and Hydrogenated Amorphous Silicon during Thermal Annealing Experiments," Applied Physics Letters, Vol. 97, No. 3, 2010, Article ID: 031918. http://dx.doi.org/10.1063/1.3464961

[46] S. Chakraborty and D. A. Drabold, "Static and Dynamic
Properties of Hydrogenated Amorphous Silicon with Voids," Physical Review B, Vol. 79, No. 11, 2009, pp. 115214-115222. http://dx.doi.org/10.1103/PhysRevB.79.115214

[47] M. B. Aksari and A. Eray, "Modeling and Optimisation of A-Si:H/C-Si Heterojunction Solar Cells," 26th European Photovoltaic Solar Energy Conference and Exhibition, Hamburg, 5-6 September 2011, pp. 1497-1502.

[48] C. Leendertz, N. Mingirulli, T. F. Schulze, J. P. Kleider, B. Rech and L. Korte, "Discerning Passivation Mechanisms at A-Si:H/C-Si Interfaces by Means of Photoconductance Measurements," Applied Physics Letters, Vol. 98, No. 20, 2011, Article ID: 202108. http://dx.doi.org/10.1063/1.3590254

[49] M. Nath, P. Chatterjee, J. Damon-Lacoste and P. Roca i Cabarrocas, "Criteria for Improved Open-Circuit Voltage in A-Si:H(N)/C-Si(P) Front Heterojunction with Intrinsic Thin Layer Solar Cells," Journal of Applied Physics, Vol. 103, No. 3, 2008, Article ID: 034506. http://dx.doi.org/10.1063/1.2838459

[50] M. Rahmouni, A. Datta, P. Chatterjee, J. Damon-Lacoste, C. Ballif and P. Roca i Cabarrocas, "Carrier Transport and Sensitivity Issues in Heterojunction with Intrinsic Thin Layer Solar Cells on N-Type Crystalline Silicon: A Computer Simulation Study," Journal of Applied Physics, Vol. 107, No. 5, 2010, Article ID: 054521. http://dx.doi.org/10.1063/1.3326945

[51] T. F. Schulze, H. N. Beushausen, C. Leendertz, A. Dobrich, B. Rech and L. Korte, "Interplay of Amorphous Silicon Disorder and Hydrogen Content with Interface Defects in Amorphous/Crystalline Silicon Heterojunctions," Applied Physics Letters, Vol. 96, No. 25, 2010, Article ID: 252102. http://dx.doi.org/10.1063/1.3455900

[52] M. Taguchi, E. Maruyama and M. Tanaka, "Temperature Dependence of Amorphous/Crystalline Silicon Heterojunction Solar Cells," Japanese Journal of Applied Physics, Vol. 47, No. 2, 2008, pp. 814-818. http://dx.doi.org/10.1143/JJAP.47.814

[53] P. Altermatt, "Models for Numerical Device Simulations of Crystalline Silicon Solar Cells-A Review," Journal of Computational Electronics, Vol. 10, No. 3, 2011, pp. 314-330. http://dx.doi.org/10.1007/s10825-011-0367-6

[54] A. G. Aberle, "Crystalline Silicon Solar Cells: Advanced Surface Passivation and Analysis," Centre for Photovoltaic Engineering, University of New South Wales, Sydney, 1999.

[55] U. Hansen and P. Vogl, "Hydrogen Passivation of Silicon Surfaces: A Classical Molecular-Dynamics Study," Physical Review B, Vol. 57, No. 20, 1998, pp. 13295-13304. http://dx.doi.org/10.1103/PhysRevB.57.13295 